\title{
DEVELOPING AND APPLYING A SCALE FOR MEASURING BASIC COMMUNICATION SKILLS OF VILLAGE EXTENSION WORKERS AT A.R.E. "A FIELD STUDY FOR VILLAGE EXTENSION WORKERS IN THREE DISTRICTS AT DAKAHLIA GOVERNORATE".
}

\section{Abd El-Magieed, M.A.M.* and A.H.M. El-Said**}

* Agricultural Extension and Rural Society Dept., Faculty of Agriculture, University of Mansoura.

** Agricultural Economic Dept., Ismailia Faculty of Agriculture, University of Suez Canal.

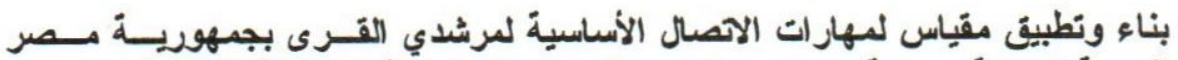

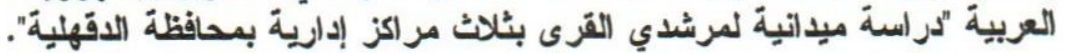

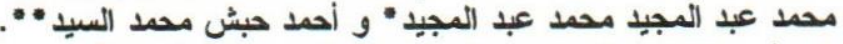

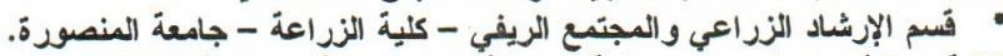

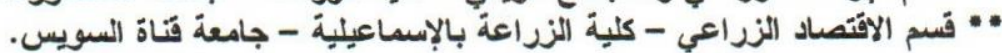

\section{الملخص}

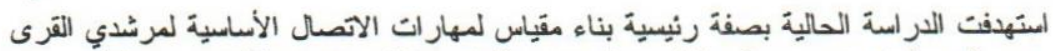

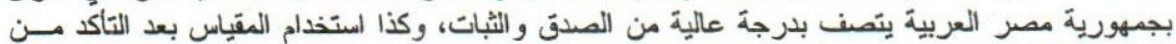

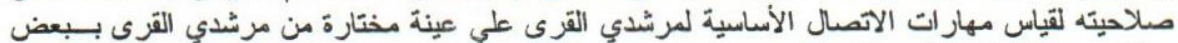

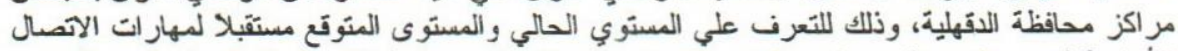

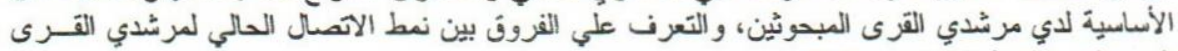

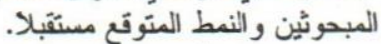

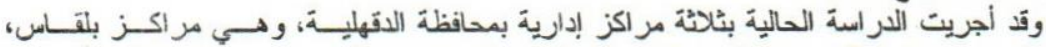

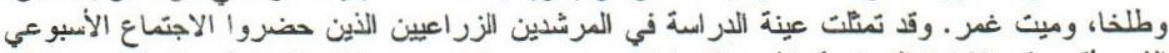

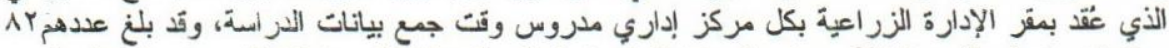

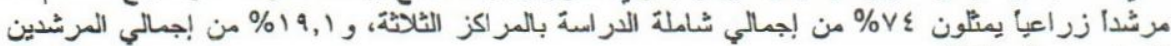
الزر اعيين بالمحافظة.

وقد استخدم الاستيبان بالمقابلة الشخصية كأسلوب لجمع البيانات الميدانية، وقد تم جمع بيانسات

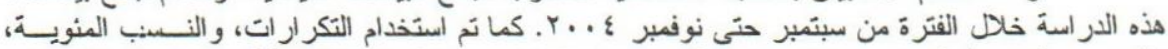

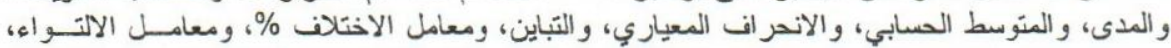

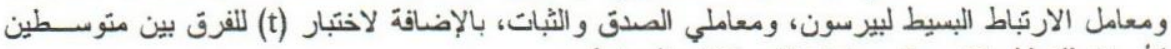

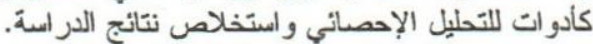

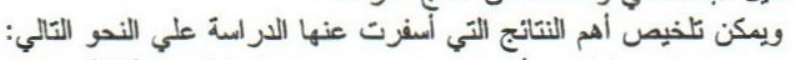

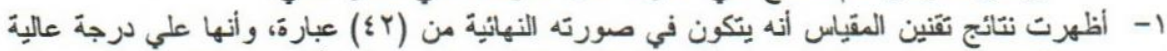

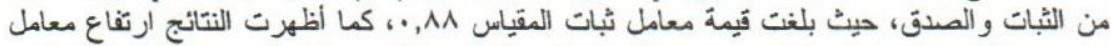

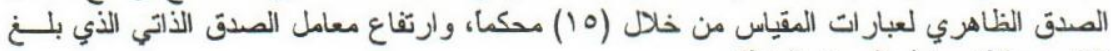

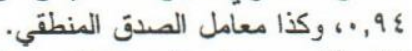
ץ- كذلك أظهرت نتائج تقنين المقياس تحقى الاتساق الداخلي وارتفاع قدرة المقياس علي التمييز، وتو افر التجانس بين نصفي المقياس.

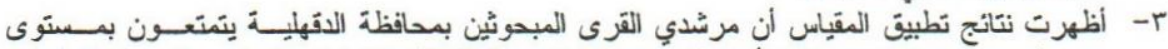

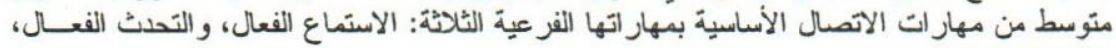




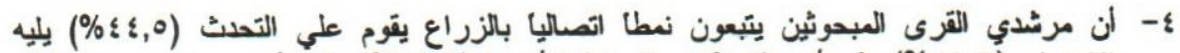

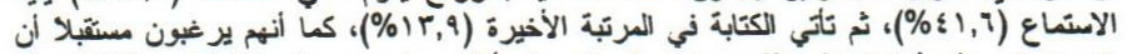

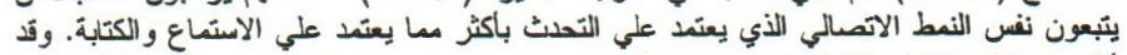

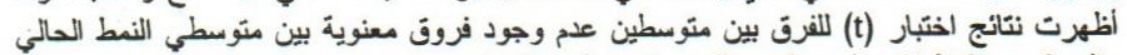
والمتوقع مستقبلا لاتصال مرشُدي القرى المبحوثُنِ بالزراع.

\section{المقدمة}

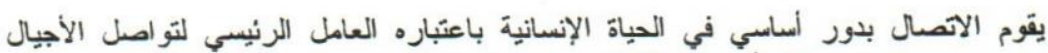

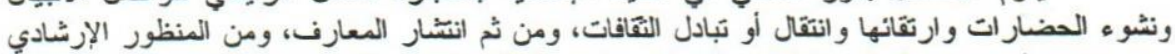

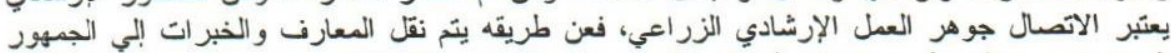

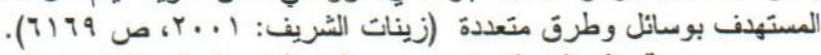

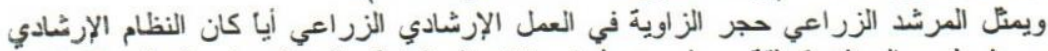

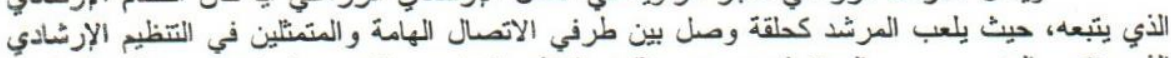

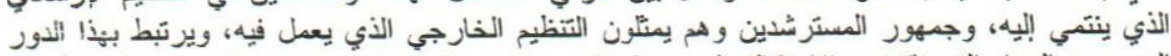

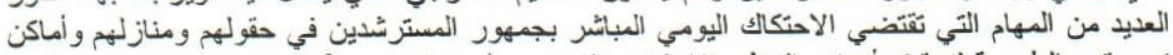

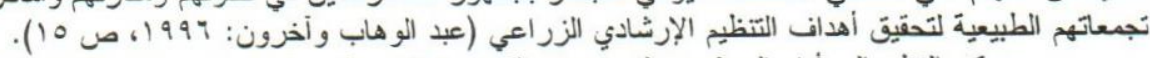

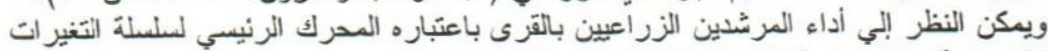

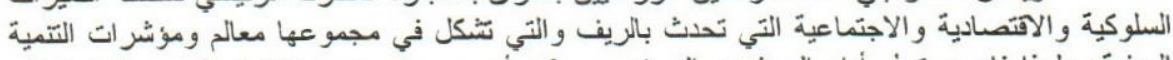

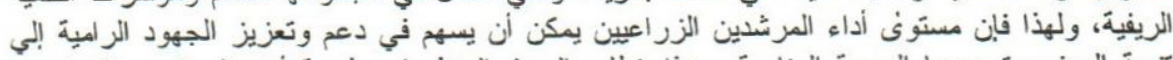

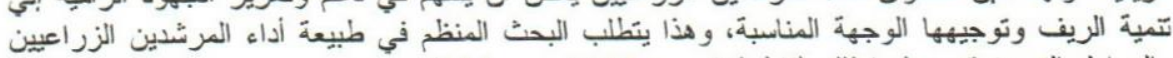

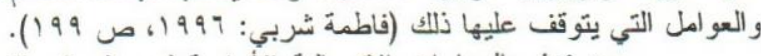

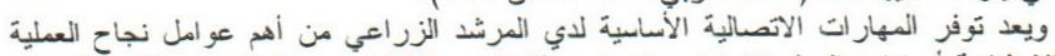

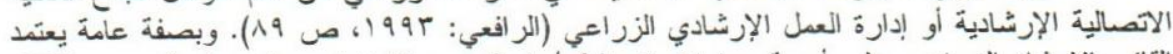

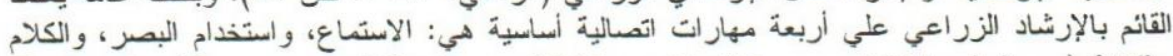

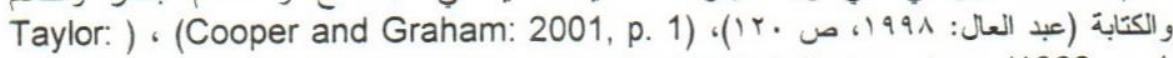

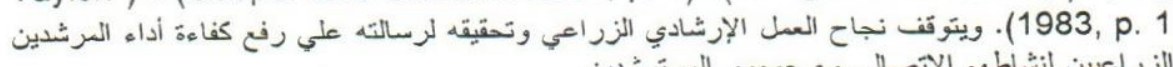

$$
\text { الاستعر اض المرجعي }
$$

يتضح من المقدمة السابقة أن الحديث عن مهارات الاتصال الأساسية لابد وأن يصاحبه تناول

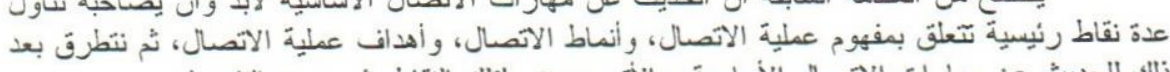

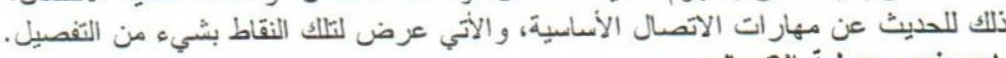

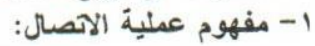

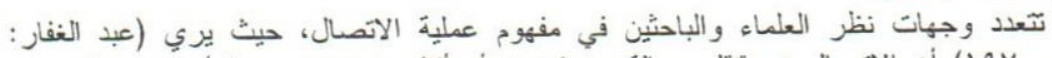

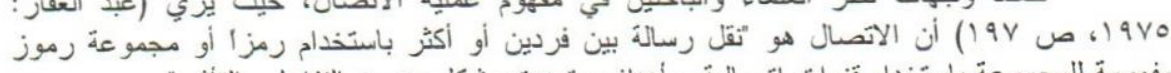

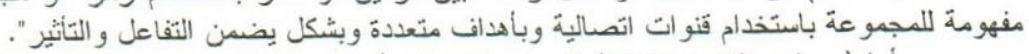

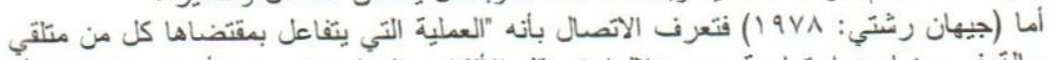

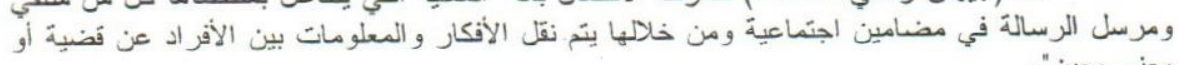
ويعرفها (Rogers: 1983, p. 69) بأنه "عملية إنسانية أساسية لتغييز السلوك". أما

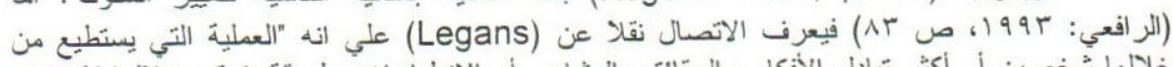

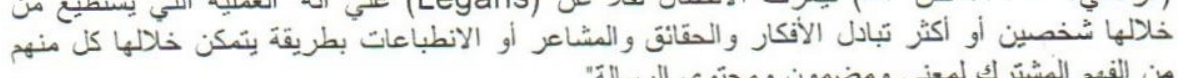

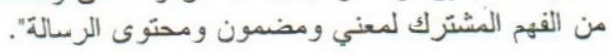




\section{J. Agric. Sci. Mansoura Univ., 30(11), November, 2005}

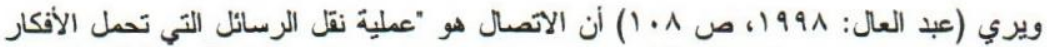

والمعاني والمشاعر من المصنر إلي المستقبل، وهي عطية تحدث حقيقة عندما يتم استقبال الرسائل الريل بو اسطة المستقبل ويقوم بتفسير هاتي". وأخيرا تعرن (Walker, et al.: 2002, p. 2) الاتصال بأنه عبارة عن "تبادل للأفكار

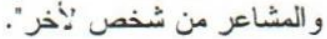

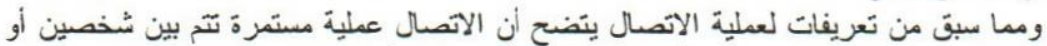

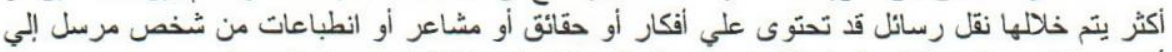

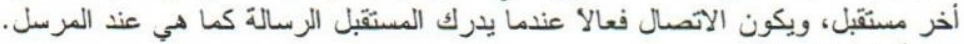

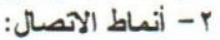

وكما تتعدد وجهات نظر العلماء والباحثين في مفهوم عملية الاتصال، تتعدد كذلك المعايير التي ولتي

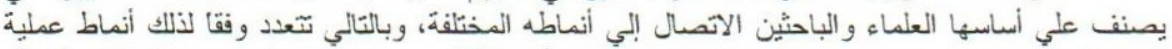

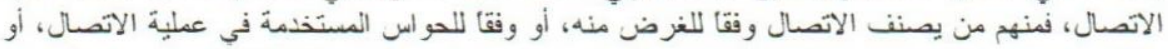

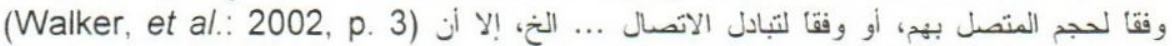

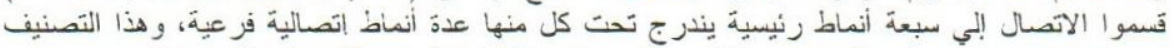

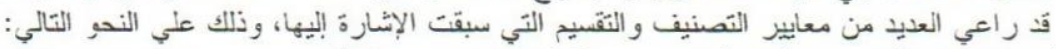

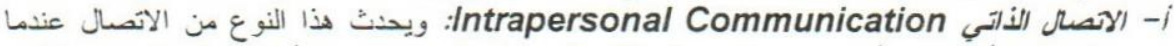

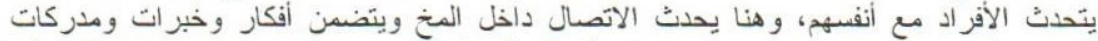

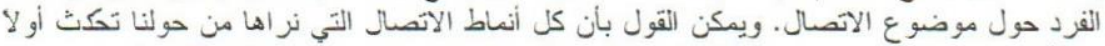

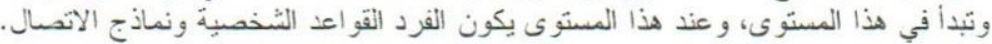

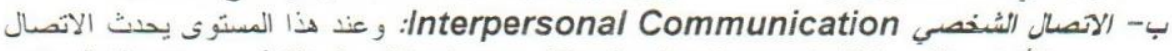

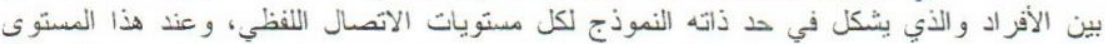

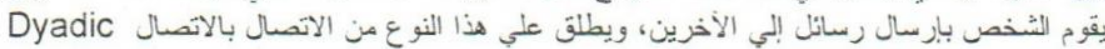
Communication

ج- الاتصلال بالمجموعات الصغيرة 'Small Group Communication: وهذا النمط يكون

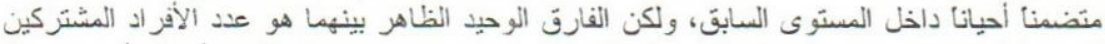

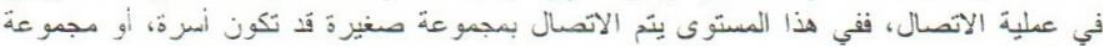

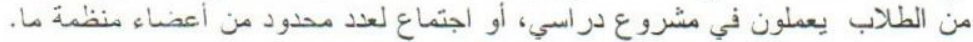

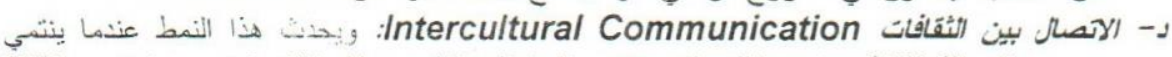

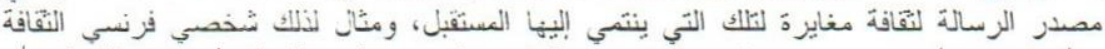

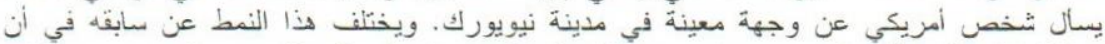

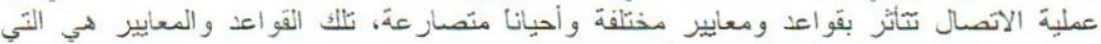

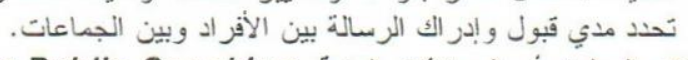

ه- الاتصال العام أو المحادثات العامة Public Communication or Public Speaking:

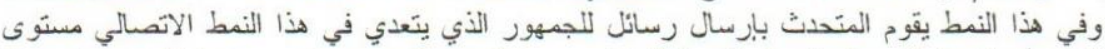

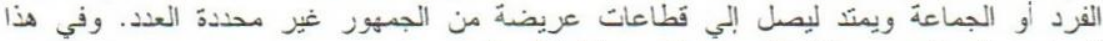
المستوى يقوم المصدر بأداء كل ما بنعلق بعملية الاتصال.

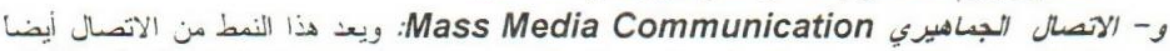

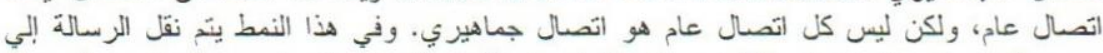

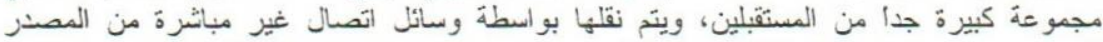

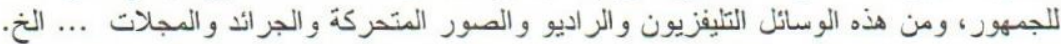

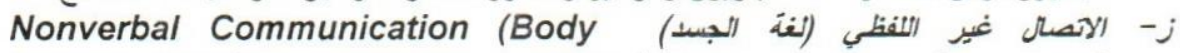
(Language)

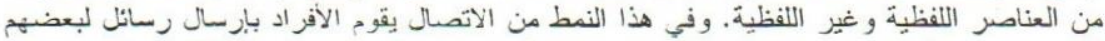

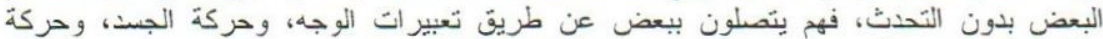

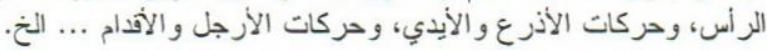




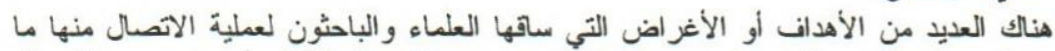

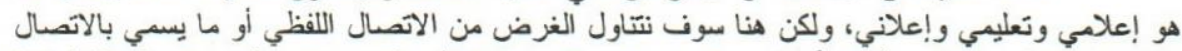

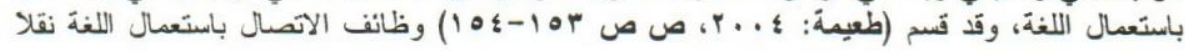

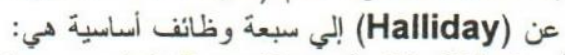

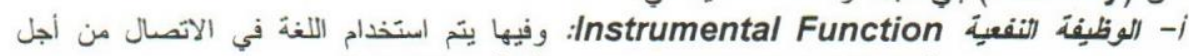

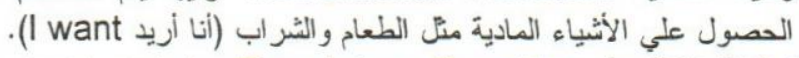

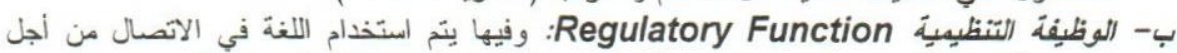

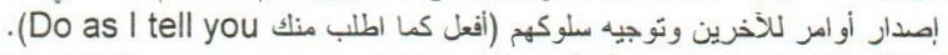

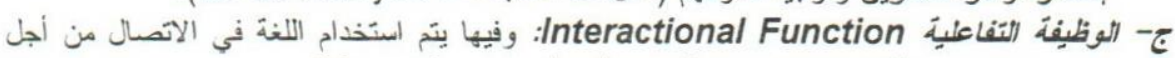

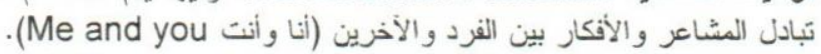

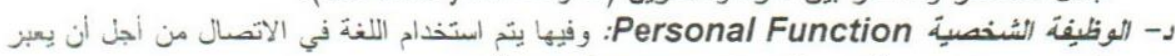
الفزد عن مشاعر ه و أفكاره (إنني قادم (Here I come).

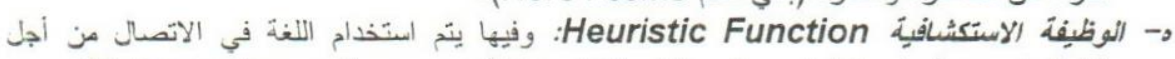

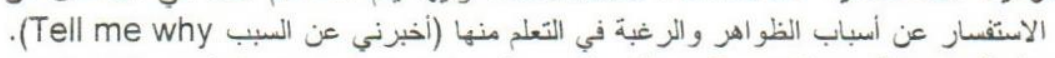

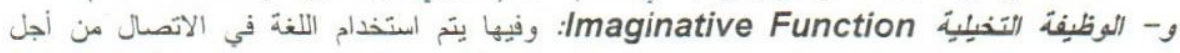

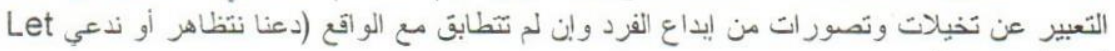
.(us pretend ز- الموظيفة البنائية Representational Function: وفيها بتت استخدام اللغة في الاتصال من

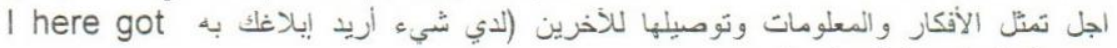

.(something to tell you مهارات الآصال الأساسية: يري (Taylor: 1983, p. 1) أنه لنجاح علية الاتصال لابد وأن بيتمتع مصدر الاتصال

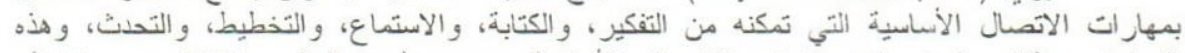

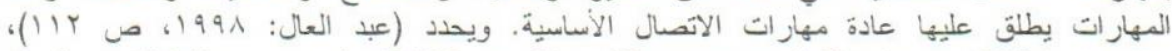
(Walker, et al:: 2002, p. 2) في أربعة العبة (Cooper and Graham: 2001, p. 1),

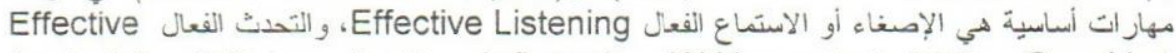
Speaking .Nonverbal Communication

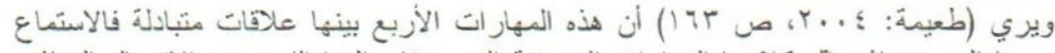

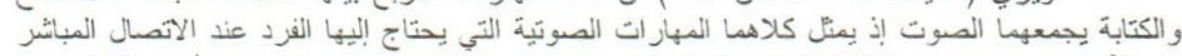

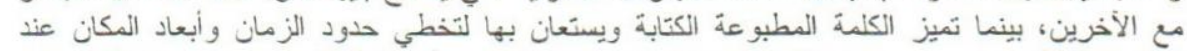

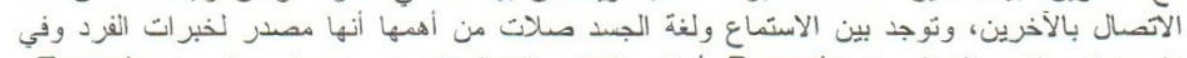

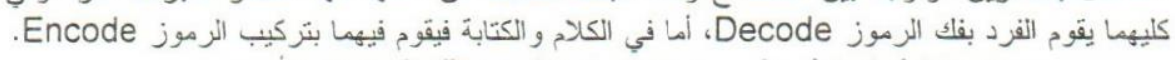

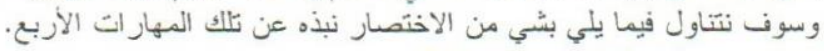

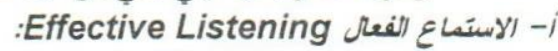

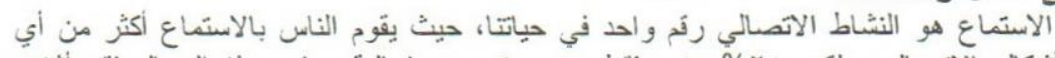

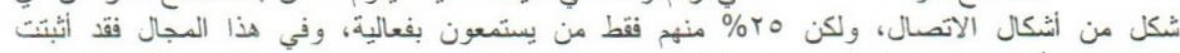

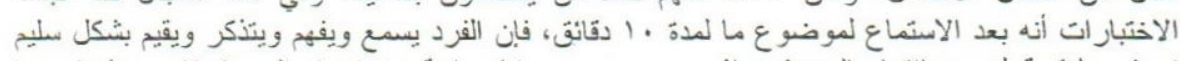

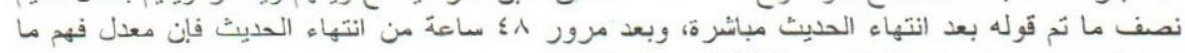

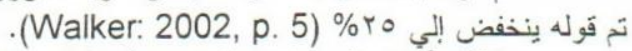

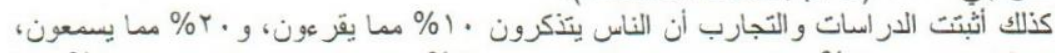

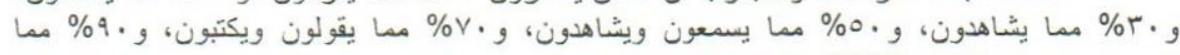
يقونون ويفعلون (Walker: 2002, p. 5). 


\section{J. Agric. Sci. Mansoura Univ., 30(11), November, 2005}

وعلية الاسنساع تنكون من ثلاثة أجز اء منساوية في الأهمية تلي عملية السماع Hearing في

حد ذاتها وهي (Walker: 2002, p. 6) تونة

التفسير Interpretation: ويتت فيها تقسير ما تم سماعه، حيث يتزتب علي التفسير الفهم أو عنم

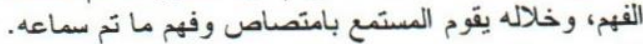

علنيها. Evaluation: وفيها يتم تقدير المعلومات التّي تم سماعها وتحديد كيفية استخذامها والبناء رالأساس. الفعل Reaction: وفيها يقوم الفرد بالبناء علي ما تم سماعه ونتائج تقييمه والعمل علي هذا

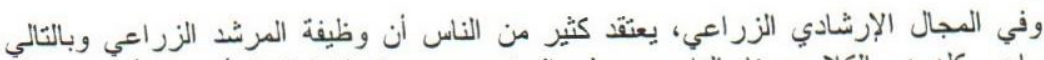

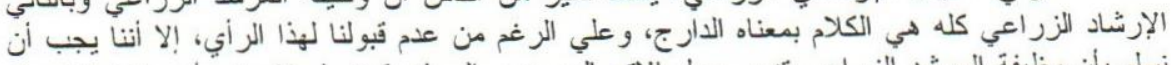

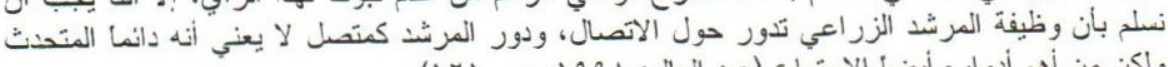

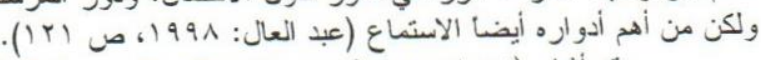

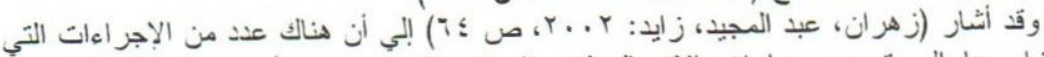

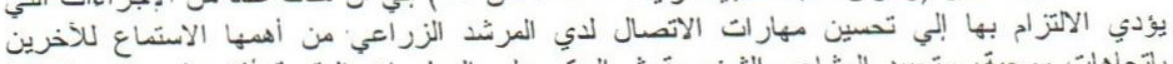

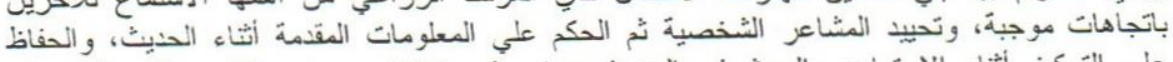

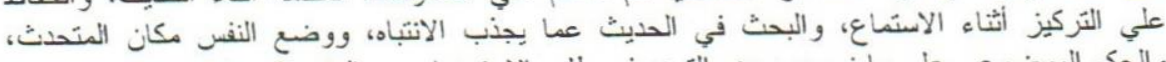

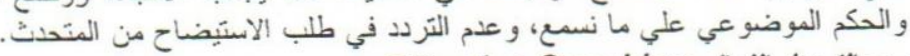

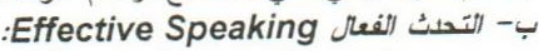

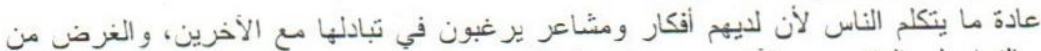

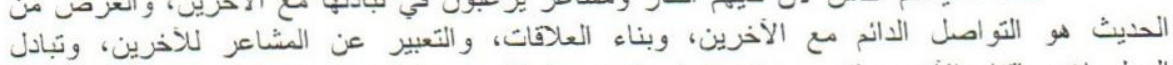

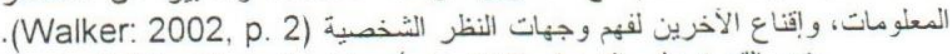

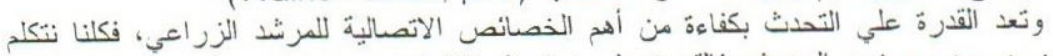

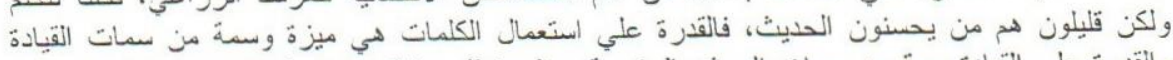

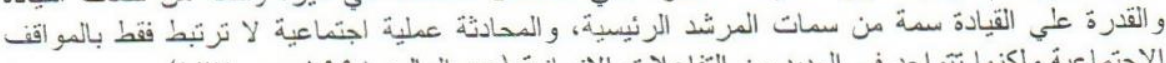

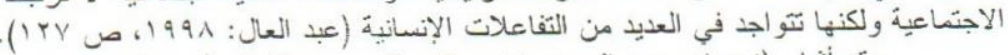

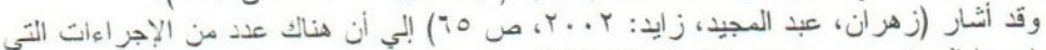

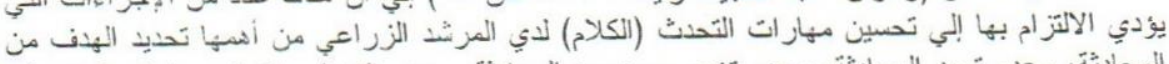

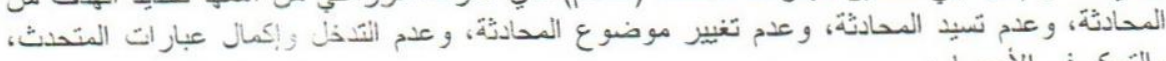

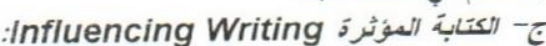

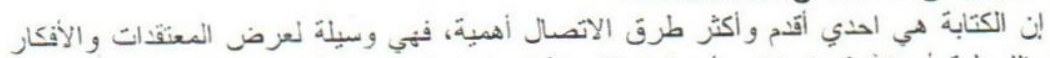

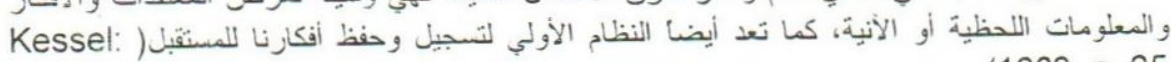
(1983, p. 25

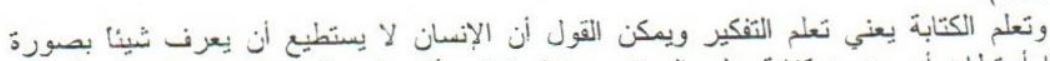

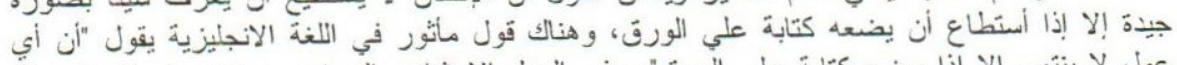

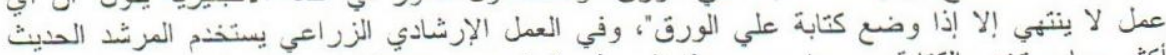

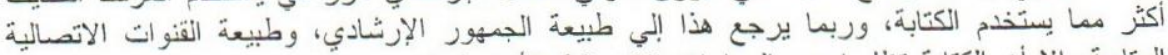

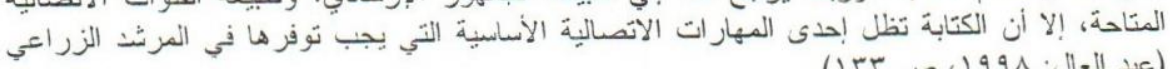

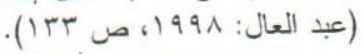

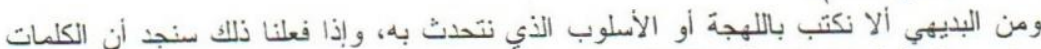

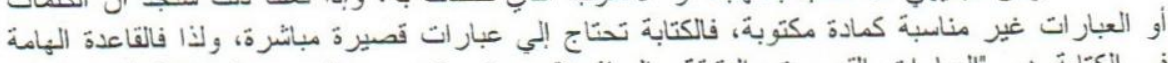

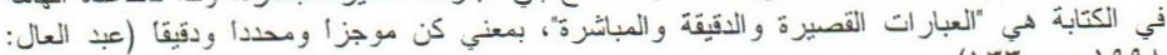

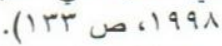

ر- استخد/م البصر (لغة الجسد) :مody Language:

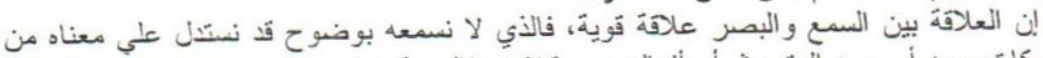

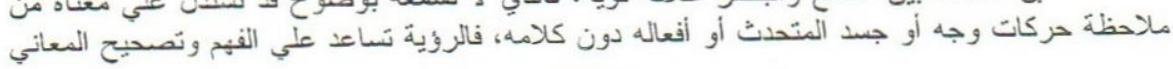




\section{Abd El-Magieed, M.A.M. and A.H.M. El-Said}

وتدعيم وتقوية الرسائل المستقبلة، والاعتماد علي الرموز البصرية (حركات الجسد والوجه) تعني أننا لا

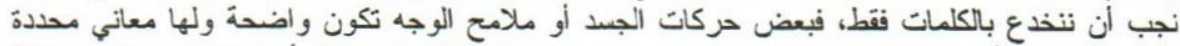

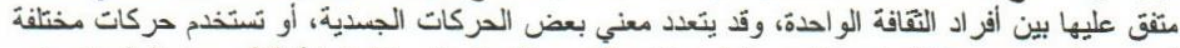

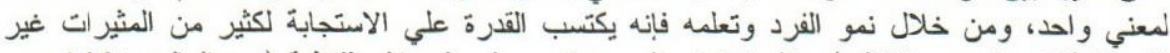

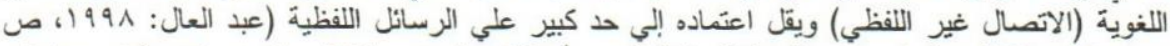

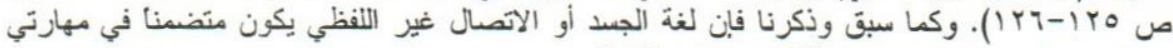
الاستماع و الحديث ولا والو وكتوفر مطلقا في مهارة الكتابة.

\section{المشكلة البحنية}

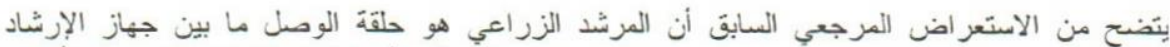

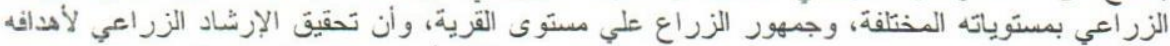

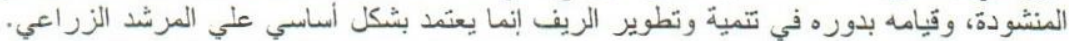

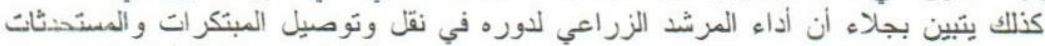

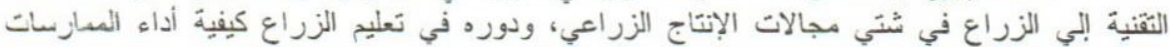

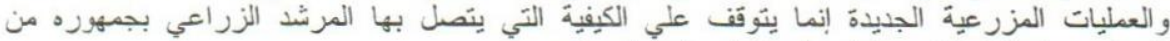

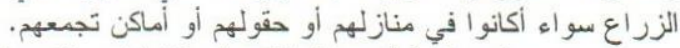

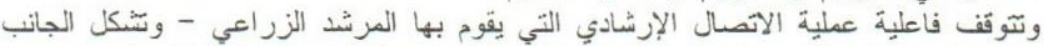

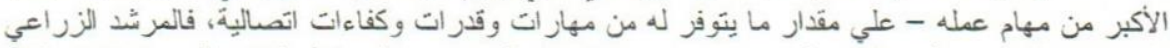

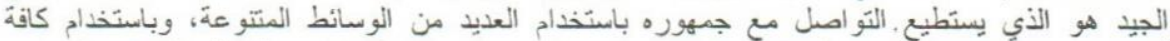

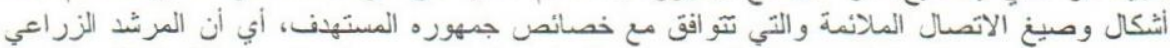

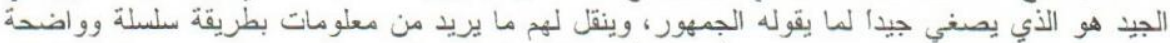

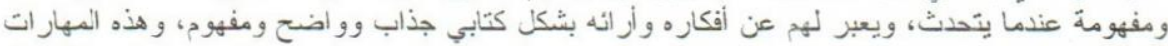

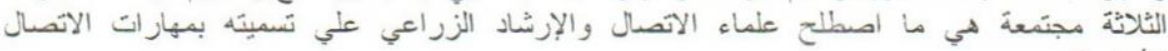
الأساسية.

ومن الملاحظ أن البحوث و الدراسات الثي أجريت في مجال الاتصال الإرشادي وفعليته إنما

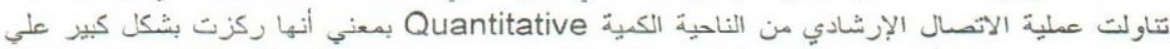

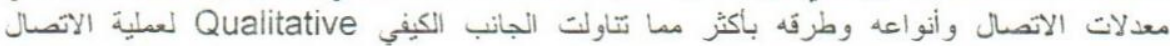

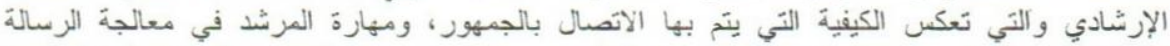

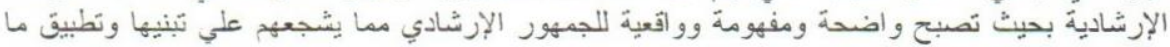
بها من توصيات و إرشادات.

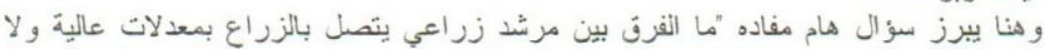

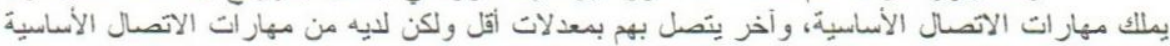

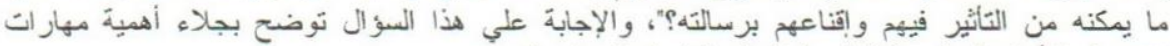

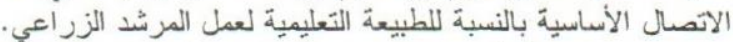
وكما أغفلت العديد من البحوث والنية الدراسات الإرشادية الجانب الكيفي في في عملية الاتصال

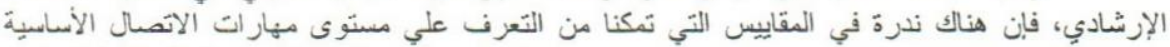

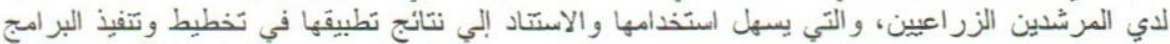

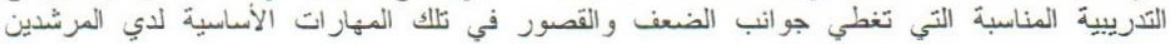

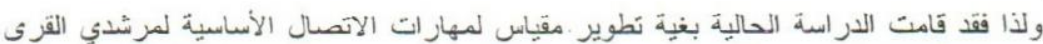
الزر اعيين.

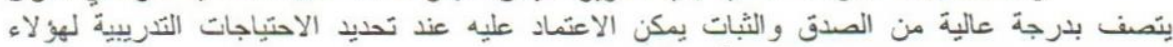
المرشدين في مجال مهار ات التهة الاتصال الأساسية. 


\section{أهداف البحث}

تستهدف هذه الأرسة بصفة رئيسبة تحقيق الأهداف البحثية التالية:

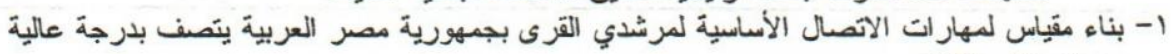

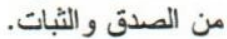

ب- استخدام المقياس بعد التأكد من صلاحيتّه لقياس مهارات الاتصال الأساسية لمرشدي القرى علي عينة

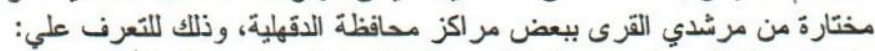

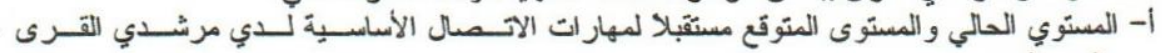

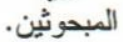

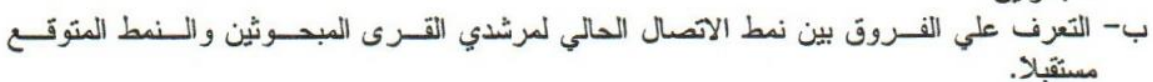

\section{الطريقةَ البحثية}

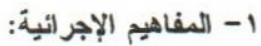

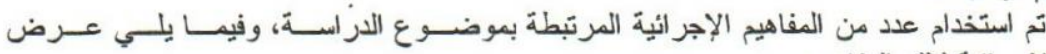

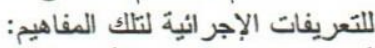

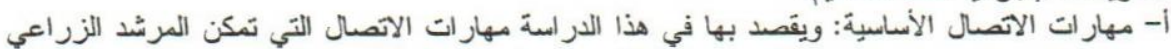

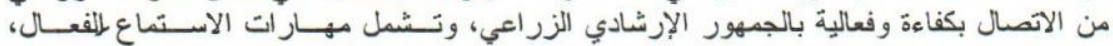

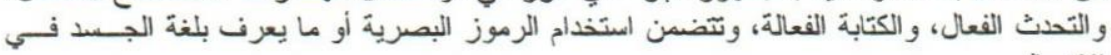

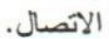

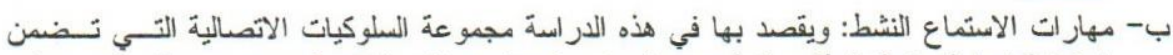

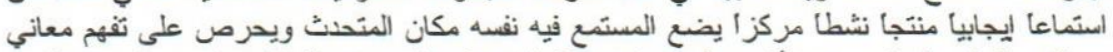

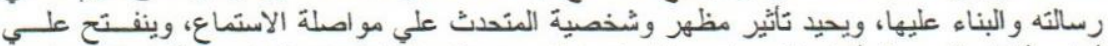

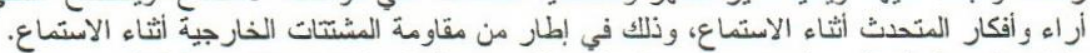

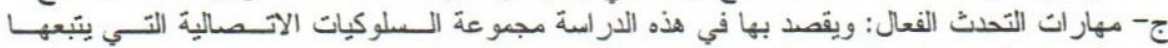

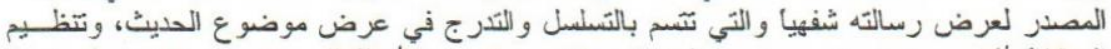

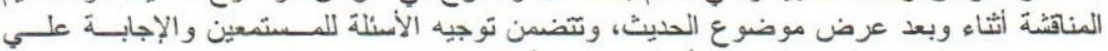

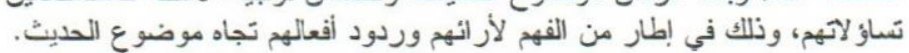

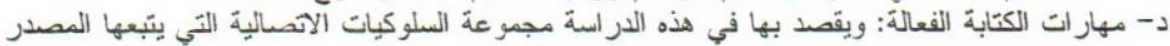

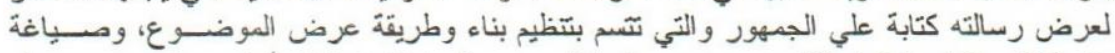

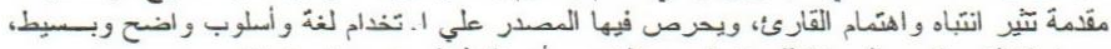

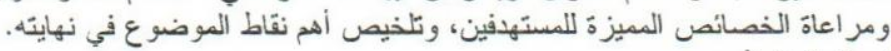

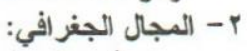

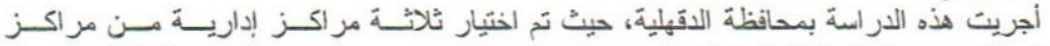

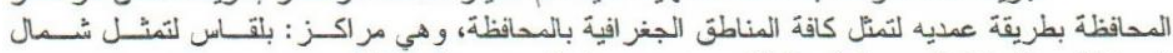

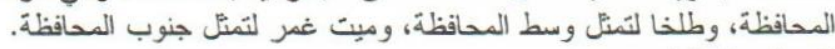

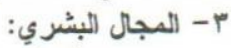

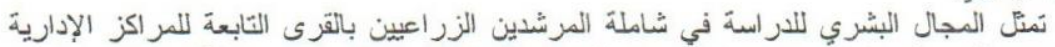

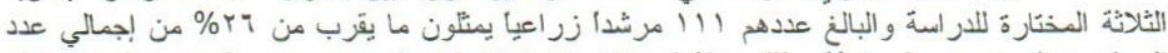

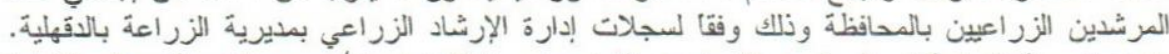

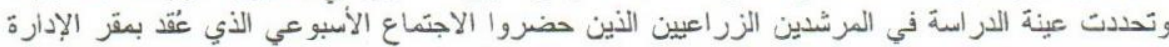

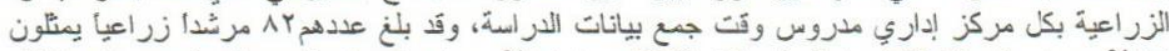

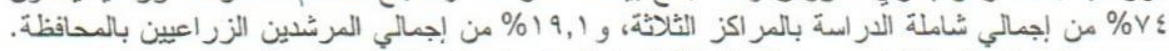
ويوضح الجدول رقم (1) توزيع عينة وشاملة الدراسة علي المر اكز الإدارية المختارة. 
Abd El-Magieed, M.A.M. and A.H.M. El-Said

جدول رقم (1): توزيع شاملة وعينة اللراسة عثي المراكز الإدارية المختارة.

\begin{tabular}{|c|c|c|c|}
\hline \multicolumn{2}{|c|}{ العينة } & \multirow{2}{*}{ الشُشاملة } & \multirow{2}{*}{ المركز } \\
\hline \% من الشاملة & العدد & & \\
\hline$v 9,0$ & ro & $\leqslant \varepsilon$ & بلقاس \\
\hline $71, \cdot$ & Yo & $\leq 1$ & ميبت غمر \\
\hline$\Lambda \leqslant, 7$ & YY & YT & طلذا \\
\hline Vr, 9 & AY & 111 & الإجملـــــي \\
\hline
\end{tabular}

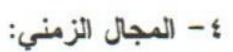

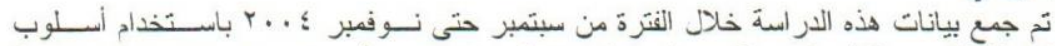

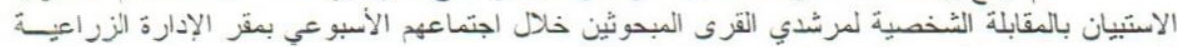

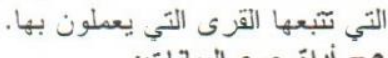

$$
\begin{aligned}
& \text { ه- أداة جمع البيانات: }
\end{aligned}
$$

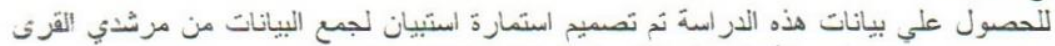

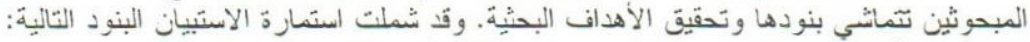

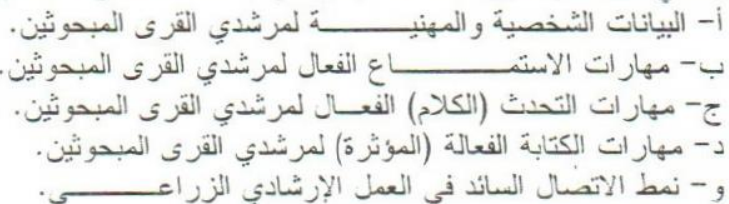

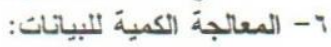

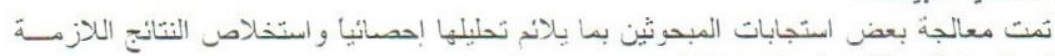

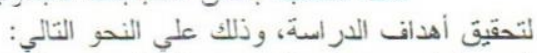

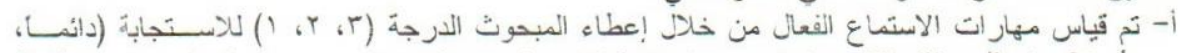

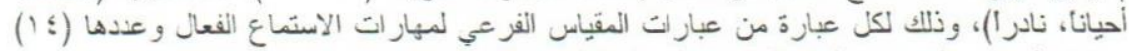

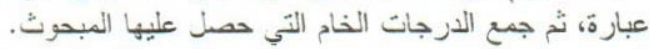

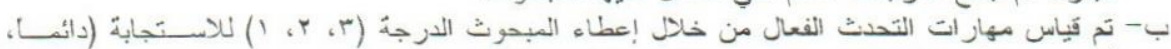

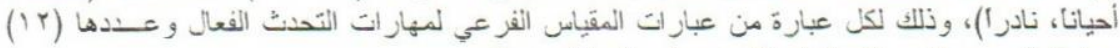

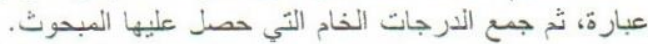

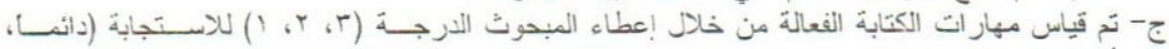

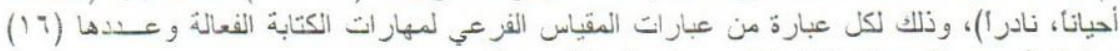

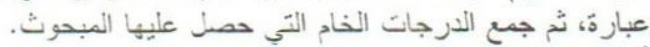
- V أدوات التحليل الإحصائي:

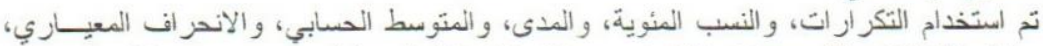

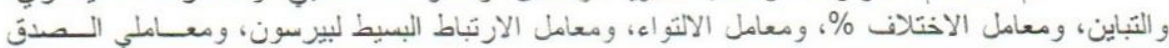

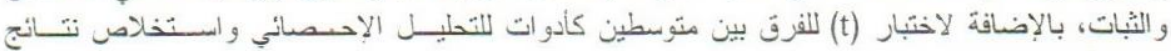
الاراسة.

\section{التنتائج ومناقشتها}

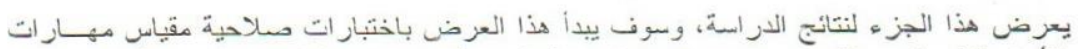

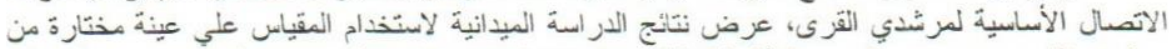

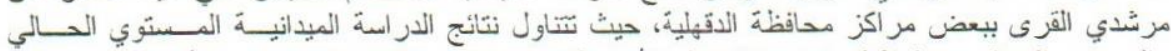

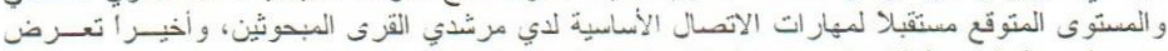

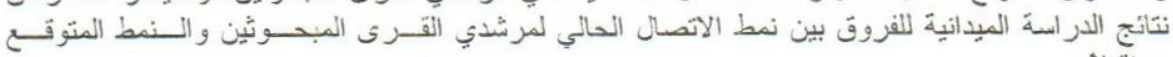




\section{J. Agric. Sci. Mansoura Univ., 30(11), November, 2005}

أولأ: نتائج اختبارات صلاحية مقياس مهارات الاتصال الأساسية لمرشدي:

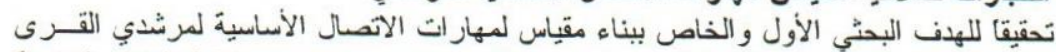

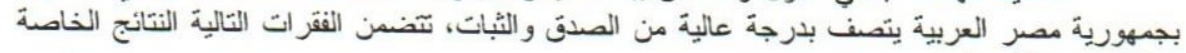

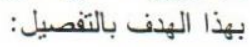

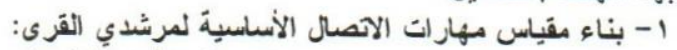

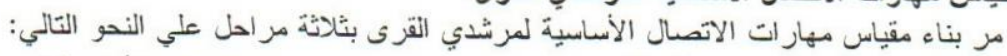

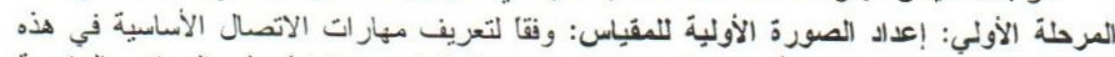

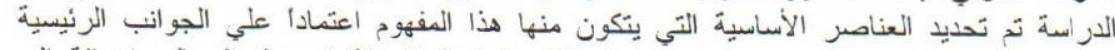

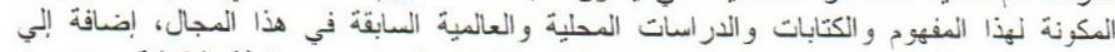

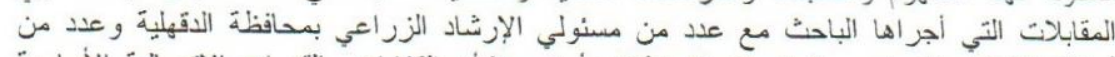

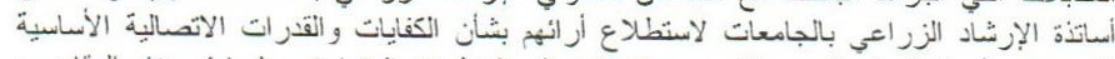

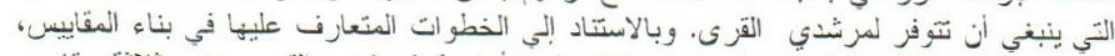

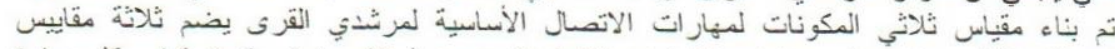

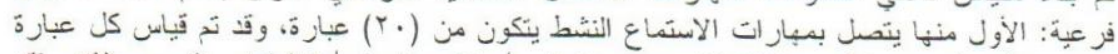

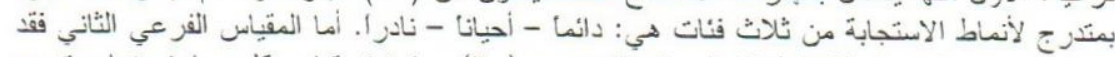

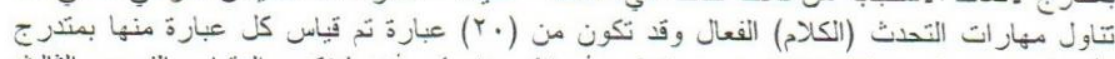

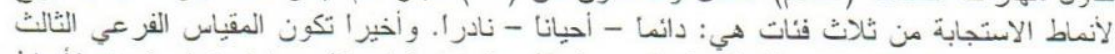

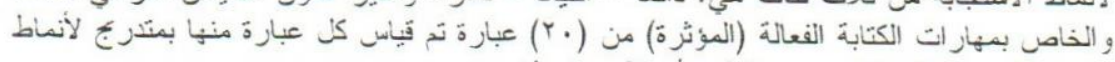

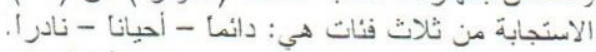

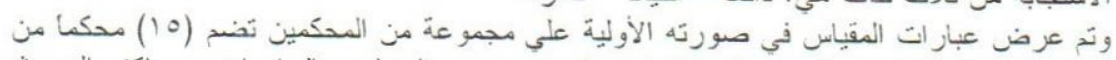

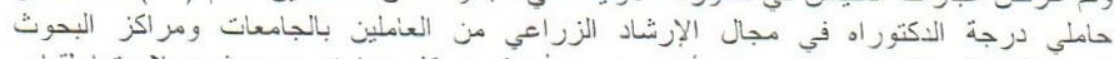

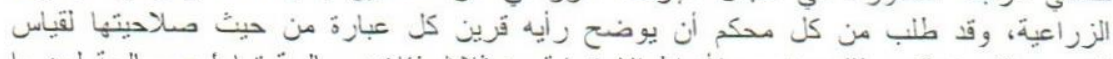

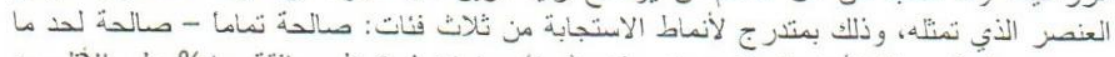

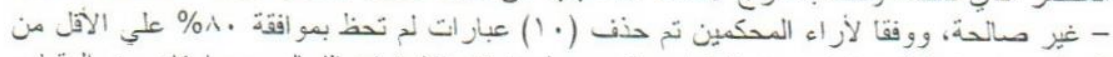

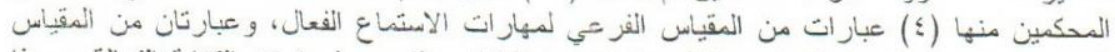

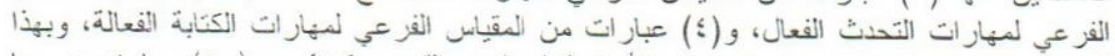

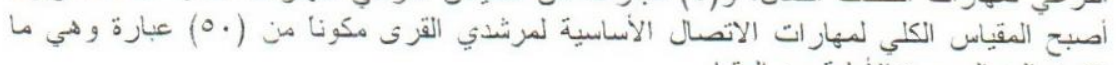

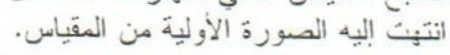

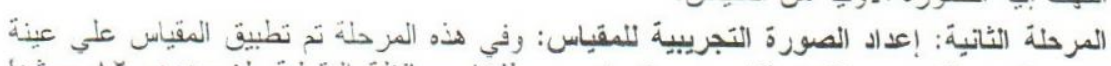

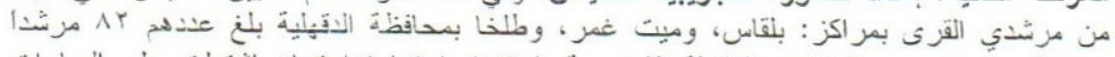

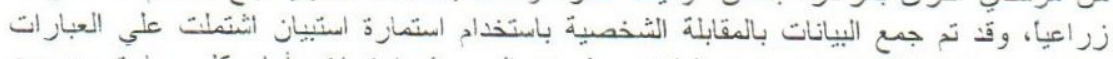

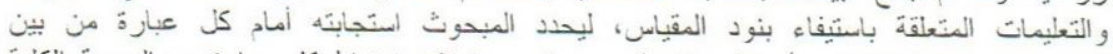

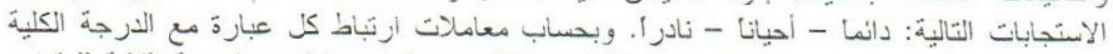

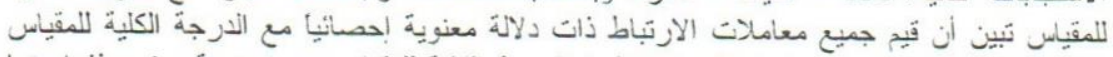

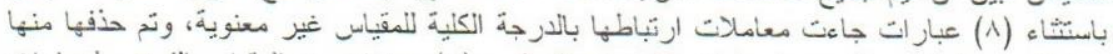

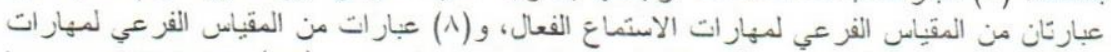

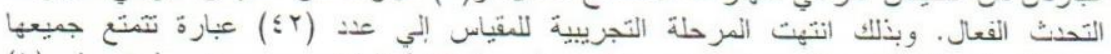

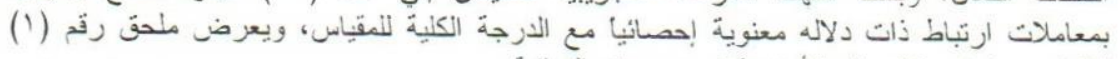

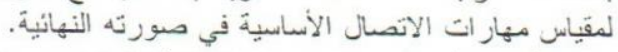

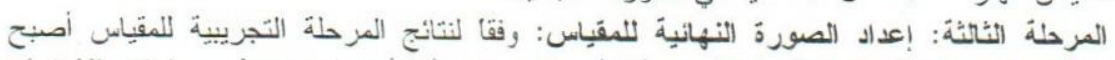

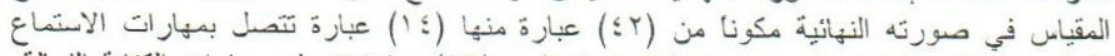

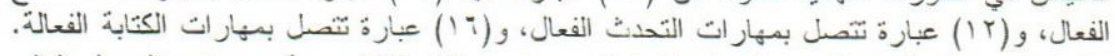

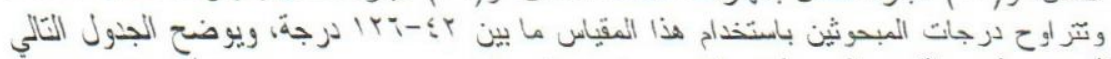

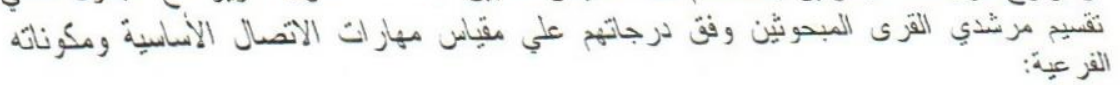




\section{Abd El-Magieed, M.A.M. and A.H.M. El-Said}

\begin{tabular}{|c|c|c|c|}
\hline مسنو ع عالي & مستوى منتوسط & مستو ض ضعيف & المقِياس \\
\hline$\leqslant Y-r Y, V$ & TY,T-YY,S & $r Y, r-1 \leq$ & 1- الاسنماع الفعــــ \\
\hline rq-rq & $r \wedge-r \mid$ & $r \cdot-1 r$ & 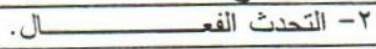 \\
\hline$\leqslant \wedge-r v, r$ & $r V, r-r T, V$ & $r 7,7-17$ & r- الكتابة الفعاله \\
\hline $179-99$ & $9 \Lambda-v 1$ & $v \cdot-\vdots \varphi$ & المقياس الإجمالي \\
\hline
\end{tabular}

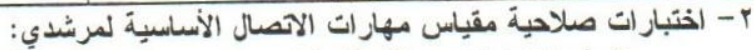

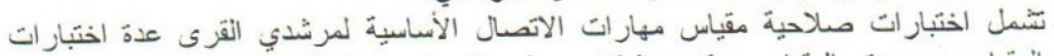

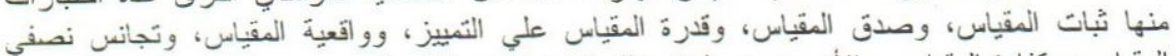

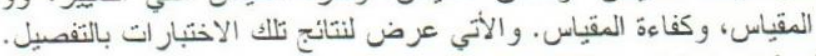

أ ثبات المقياس Scale Reliability

لتحديد معامل ثبات المقياس تم استخدام معادلة كرونباخ ألفا Cronbach a باستخدام معادلة

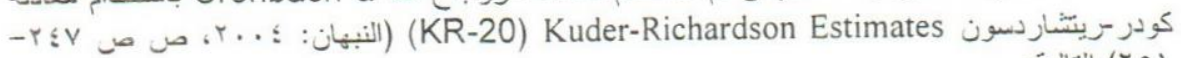

$$
\alpha=\frac{n}{n-1}\left(1-\frac{\sum S_{1}{ }^{2}}{S_{r}^{2}}\right)
$$

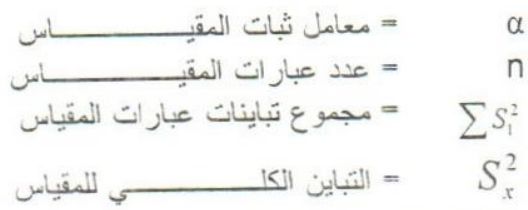

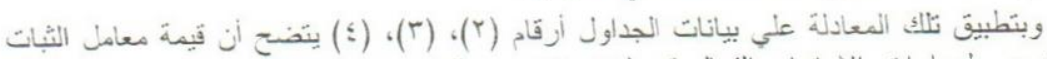

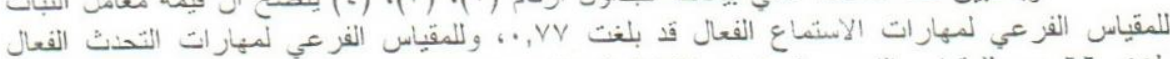

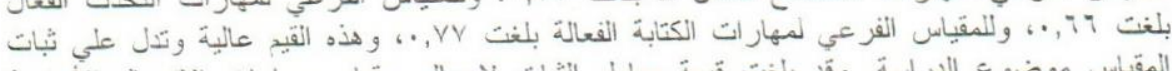

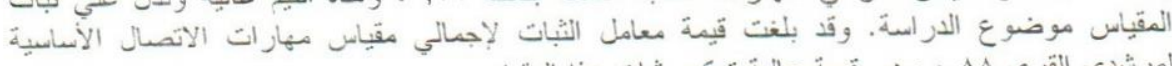

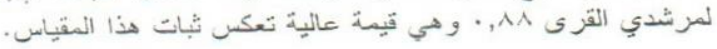

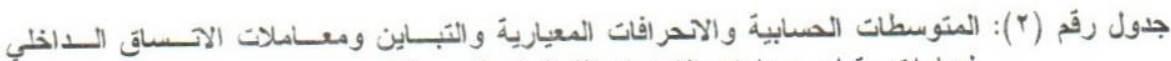

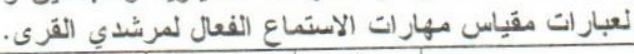

\begin{tabular}{|c|c|c|c|c|c|}
\hline $\begin{array}{l}\text { معامل الآساةق } \\
\text { (r) الداخلي }\end{array}$ & التبَاين & الالحير افت & المستوسط & العباردة & المهارات الفرعية \\
\hline., 25 & $\therefore 0$ & $\cdot, V^{\prime}$ & 1,0 & 1 & \multirow{2}{*}{ التركيز أثتاء الاستماع } \\
\hline., $0 \mathrm{~V}$ & $\cdot, i$ & $\theta, \mathrm{VV}$ & 1,0 & $r$ & \\
\hline., 71 & $\cdot, Y$ & $\cdot, \lambda r$ & $1, v$ & $r$ & \multirow{2}{*}{ فهح موضوع المحادئة } \\
\hline$\cdot, r$ & $\cdot, 7$ & $\cdot, \lambda$. & 1,5 & 9 & \\
\hline , TY T & $\cdot, 4$ & $\cdot, \wedge$. & $1, \Lambda$ & 7 & \multirow{3}{*}{ مقاومة المشتَّات الخارجية أثناء } \\
\hline$\cdot, r$ & $\cdot, r$ & $\cdot, 7$ & $1, \varepsilon$ & $\Lambda$ & \\
\hline$\cdot, Y Y$ & $\therefore, 0$ & $\cdot, \gamma$. & 1,1 & 1. & \\
\hline$\because, T T$ & $\cdot, Y$ & $\cdot, \lambda T$ & $1, v$ & v & \multirow{4}{*}{ 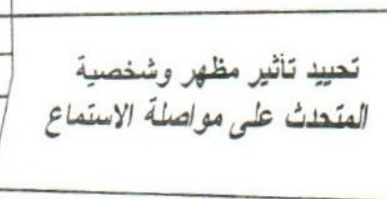 } \\
\hline$\because, 70$ & $\cdot, y$ & $\cdot, \lambda T$ & $1, \mathrm{~V}$ & ir & \\
\hline 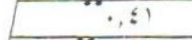 & $\cdot, 0$ & 1,5 & 1,5 & 15 & \\
\hline$\therefore$. 9 & $\cdot, 0$ & 1,5 & 1,5 & 16 & \\
\hline$\because, \leqslant$ & 0,0 & $\cdot, 79$ & 1,5 & $\leqslant$ & \multirow{3}{*}{ الافتاح على أراء و أفكار المتحدث } \\
\hline$\theta, \leqslant$ & 0,7 & $\therefore, V_{0}$ & 1,1 & 0 & \\
\hline., $0 \leq$ & $\cdot, i$ & $\cdot, V Y$ & 1,0 & 11 & \\
\hline
\end{tabular}


J. Agric. Sci. Mansoura Univ., 30(11), November, 2005

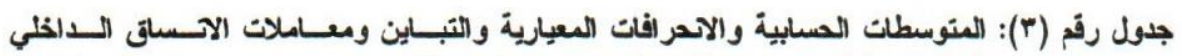

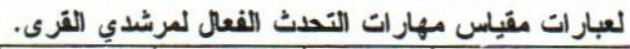

\begin{tabular}{|c|c|c|c|c|c|}
\hline 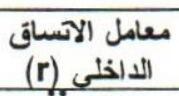 & التباين & الآِحر اف & المستوسط & العبارة & المهارات الفرعية \\
\hline$\cdot, \Gamma 1$ & $\cdot, \mathrm{V}$ & $\cdot, 10$ & 1,9 & 0 & \multirow{2}{*}{ التسلسل و التّلرج في عرض الحذيث } \\
\hline$\cdot, \mathrm{YV}$ & $\cdot, \mathrm{V}$ & $\cdot, \wedge \leq$ & $r, \cdot$ & $\mathrm{v}$ & \\
\hline., 01 & $\cdot, 7$ & $\cdot, \mathrm{Vq}$ & $1, \mathrm{~V}$ & $r$ & \multirow{3}{*}{ تنظيم المناقشة موضوع أثناء وبعد } \\
\hline$\cdot, 71$ & $\cdot, \mathrm{V}$ & $\cdot, \lambda T$ & $1, \Lambda$ & 7 & \\
\hline$\cdot$, ir & $\cdot, 0$ & $\cdot, V 7$ & $1, V$ & Ir & \\
\hline$\cdot, \Gamma Y$ & $\cdot, \mathrm{V}$ & $\cdot, \wedge 7$ & $r, r$ & $\Lambda$ & \multirow{2}{*}{ توجيه الأسئلة للمستمعين } \\
\hline$\cdot, r q$ & $\cdot, 0$ & $\cdot, \mathrm{V} \cdot$ & 1,7 & 11 & \\
\hline$\cdot, r$ & $\cdot, \mathrm{V}$ & $\cdot, 10$ & 1,9 & 9 & \multirow{2}{*}{ الإجابة عذى أسنلة المستمعين } \\
\hline$\cdot, r \leq$ & $\cdot, \mathrm{V}$ & $\cdot, \lambda \leq$ & 1,9 & 1. & \\
\hline$\therefore, \leqslant$ & $\cdot, 0$ & $\cdot, v \leq$ & 1,1 & 1 & \multirow{3}{*}{ فهخ أراء وردود أفعال } \\
\hline., 00 & $\cdot, \Lambda$ & $\cdot, 9 T$ & 1,1 & $r$ & \\
\hline$\cdot, 71$ & $\cdot, \mathrm{V}$ & $\cdot, 10$ & $1, v$ & 5 & \\
\hline
\end{tabular}

جذول رقم (؟) : المتوسطات الحسابية و الآحر افات المعيارية و التباين ومعاملات الآنساق الداخلي

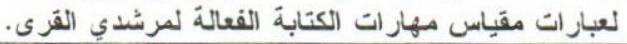

\begin{tabular}{|c|c|c|c|c|c|}
\hline معامل الآتساق & التباين & المعياري اف & المتوسط & رقبّم & المهارات الفرعية \\
\hline$\cdot, Y V$ & $\cdot, 7$ & $\cdot, V V$ & 1,1 & $\Lambda$ & \multirow{4}{*}{ تنظيم بناء وطريقة عرض الموضوع } \\
\hline$\cdot, 0 \leq$ & $\cdot, \mathrm{V}$ & $\cdot, \lambda r$ & 1,7 & 9 & \\
\hline$\cdot r v$ & $\cdot, 7$ & $\cdot, \lambda Y$ & 1,0 & ir & \\
\hline$\therefore, 0$ & $\cdot .9$ &., $9 \pi$ & 1,9 & 17 & \\
\hline$\cdot, r r$ &., 0 & $\cdot, \mathrm{V} \leq$ & 1,5 & $\leqslant$ & \multirow{3}{*}{ صياغة مقدمة تثير انتباد و اهتمام } \\
\hline $0, r \leq$ & .0 & $\cdot, V Y$ & $1, V$ & 0 & \\
\hline$\because, V Y$ & $\cdot, \lambda$ & $\cdot, \lambda \wedge$ & $1, V$ & $i$ & \\
\hline .01 & $\cdot, 5$ & $\cdot, 7 i$ & 1,5 & $r$ & \multirow{3}{*}{ استخدام لفةَ وأسطوب و واضح } \\
\hline$\cdot r v$ &., 0 & $\cdot, 79$ & 1,0 & v & \\
\hline$\cdot, r$ & $\cdot, i$ & $\cdot, V \vee$ & $1, V$ & 11 & \\
\hline$\cdot, r \lambda$ & $\cdot, 0$ & $\cdot, V Y$ & 1,0 & 1 & \multirow{4}{*}{ 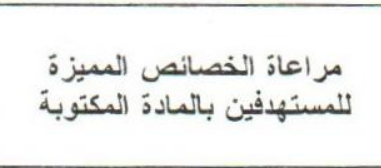 } \\
\hline., 01 & $\cdot, 7$ & $\cdot, \mathrm{VV}$ & 1,0 & $r$ & \\
\hline., 01 & $\cdot, \mathrm{V}$ & $\cdot, 10$ & $1, \Lambda$ & Ir & \\
\hline$\cdot, r r$ & $\cdot, 1$ & $\cdot, V^{-1}$ & 1,0 & 15 & \\
\hline$\cdot, i 0$ & $\cdot, \mathrm{V}$ & $\cdot, \lambda T$ & 1,0 & 1. & \multirow{2}{*}{ تلخيص أهم نقاط الموضوع في نهي } \\
\hline$\cdot, 00$ & $\cdot, i$ & $\cdot, 1 \times 9$ & $1, v$ & 10 & \\
\hline
\end{tabular}
المصدر : استسارات الاسنبيان

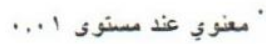
" معنوي عند مسنوى ه.,. التباين الكلى للمقيّاس = rr,T.

ب-صدق المقياس Scale Validity:

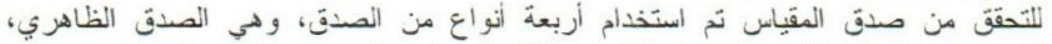

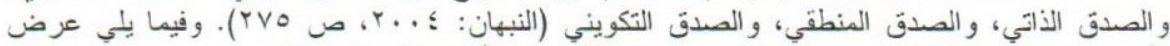

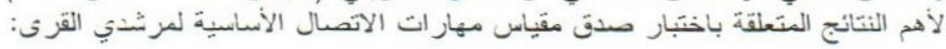


الصدق الظاهري Face Validity: أظهرت النتانج أن عبارات مقياس مهارات الاتصال

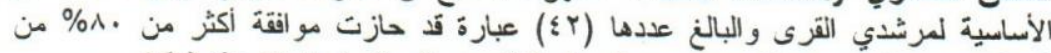

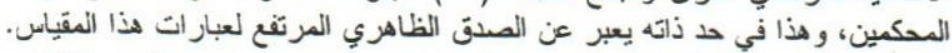

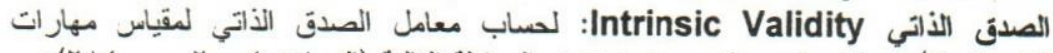

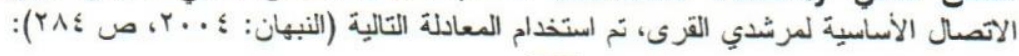

$$
r_{x y}=\sqrt{r_{x x}}
$$

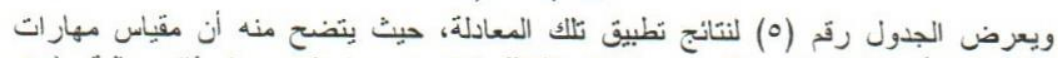

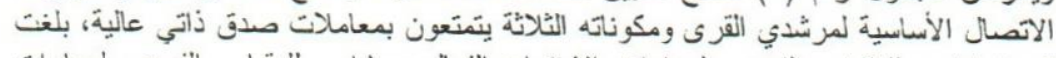

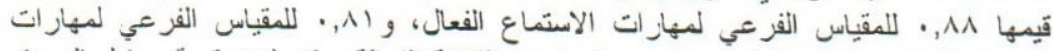

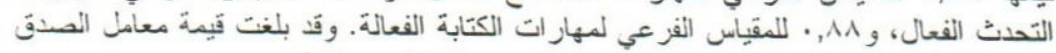

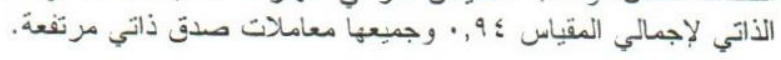

جدول رقم (ه):معامني الثبات و التصدق الذاتي لمكونات مقياس مهارات الاتصال الأساسية لمرثُشي

\begin{tabular}{|c|c|c|}
\hline معامل الصدق & معامل الثُبات & مكونات المقيّاس \\
\hline$\cdot, \lambda \Lambda$ & $\cdot, \mathrm{VY}$ & 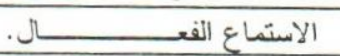 \\
\hline$\cdot, \lambda$ & $\cdot, 74$ & 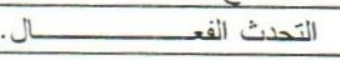 \\
\hline$\cdot \lambda A$ & $\cdot, \mathrm{VV}$ & 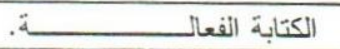 \\
\hline., $9 \leqslant$ & $\cdot, \mathrm{AN}$ & إجمالي المقياس \\
\hline
\end{tabular}

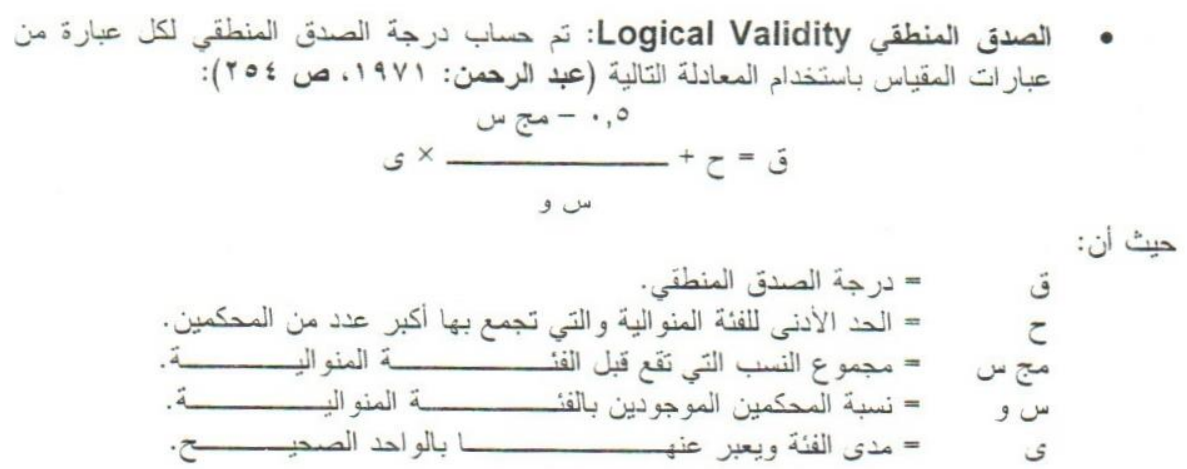

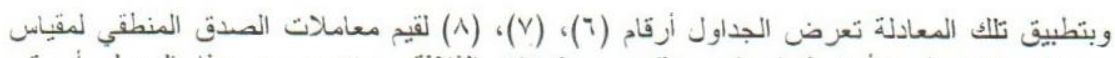

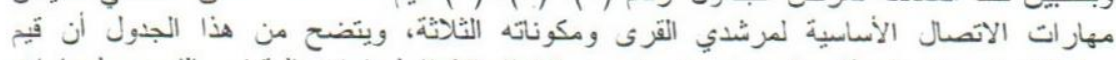

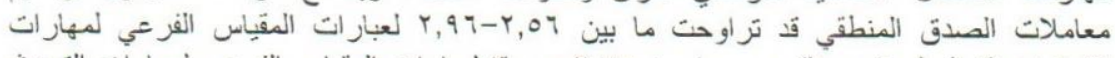

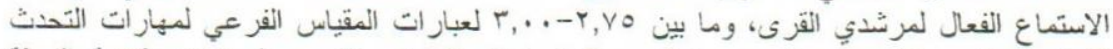

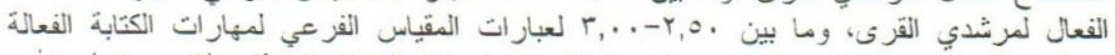

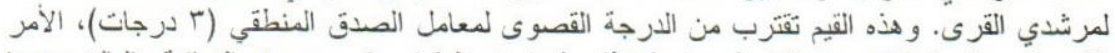

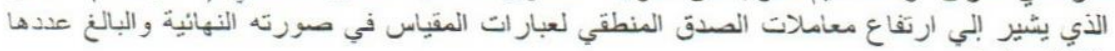

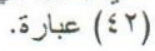

الصدق التكويني أو الآساق الاخلي Internal Consistency: الصدق التكويني يعبز

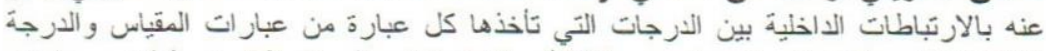

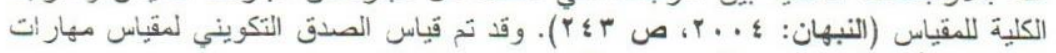
الاتصال الأساسية لمرشدي القزى من خلال محورين رئيسيين ها: 


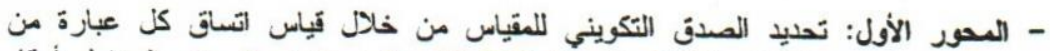

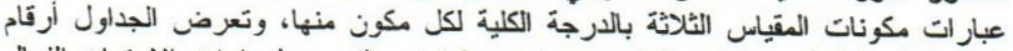

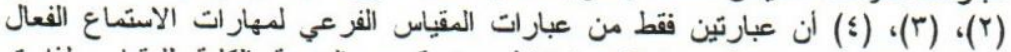

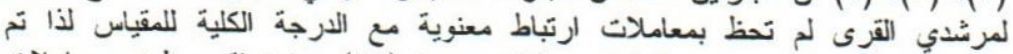

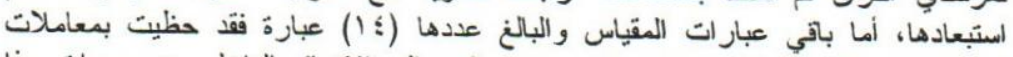

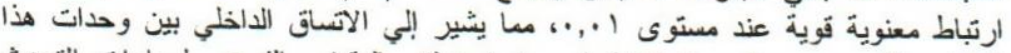

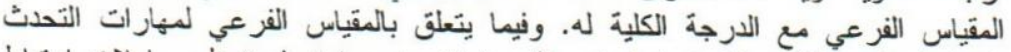

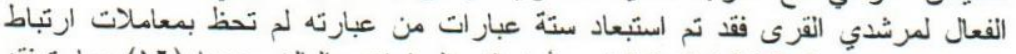

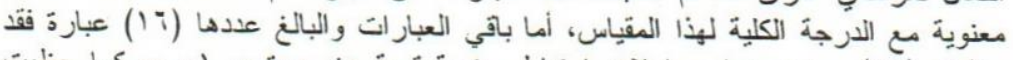

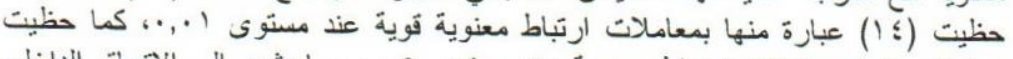

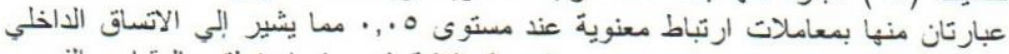

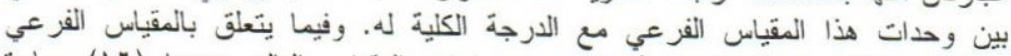

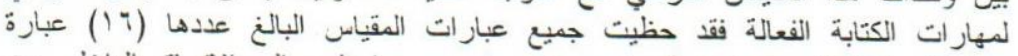

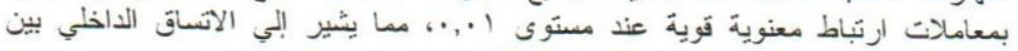

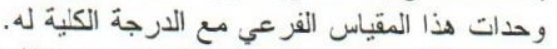

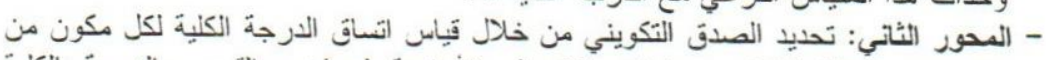

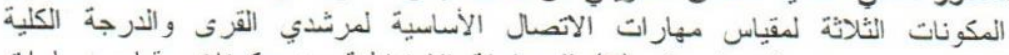

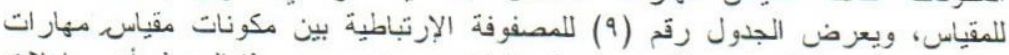

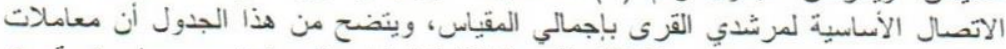

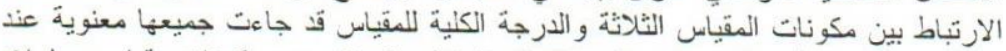

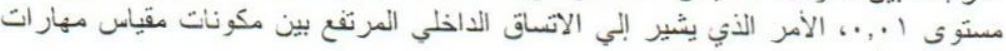
الاتصال الأساسية لمرشدي القزى المي.

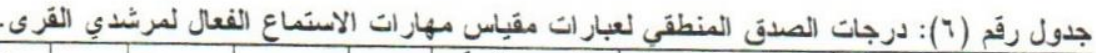

\begin{tabular}{|c|c|c|c|c|c|c|c|c|c|c|c|}
\hline \multirow{2}{*}{ المنطق } & \multirow[b]{2}{*}{ 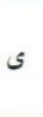 } & \multirow[b]{2}{*}{ س و } & \multirow[b]{2}{*}{ هـ س } & \multirow[b]{2}{*}{$\tau$} & \multicolumn{2}{|c|}{ غير صاحة } & \multicolumn{2}{|c|}{ صالحةٌ لحل ما } & \multicolumn{2}{|c|}{ صالحة تماما } & \multirow[b]{2}{*}{ r } \\
\hline & & & & & $\%$ & عدد & $\%$ & عدد & $\%$ & عدد & \\
\hline$r, \lambda \lambda$ & 1 & $\cdot, \lambda$. & $\cdot, r$. & $r, 0$ & $\cdot, \cdot V$ & 1 & $\cdot, 1 T$ & T & $\cdot, \wedge$ & IT & 1 \\
\hline$r, \lambda Y$ & 1 & $\cdot, V T$ & $\cdot, r V$ & $r, 0$ & - & - & $\cdot, \mathrm{rV}$ & $\leqslant$ & $\cdot, \mathrm{Vr}$ & 11 & $r$ \\
\hline$r, \Lambda \Lambda$ & 1 & $\cdot, \wedge$ & $\cdot, r$ & $r, 0$ & $\cdot, 1 T$ & $r$ & $\cdot, \cdot V$ & 1 & $\cdot, \wedge$ & IT & $r$ \\
\hline T,YO & 1 & $\cdot$, iv & $\cdot, r T$ & $T, 0$ & $\cdot, \cdot V$ & 1 & $\cdot, \mathrm{rV}$ & $\leqslant$ & $\cdot, \mathrm{TV}$ & 1. & $\varepsilon$ \\
\hline r,TV & 1 & $\cdot, i$ & $\cdot, \leqslant$ & $r, 0$ & $\cdot, Y$ & $r$ & $\cdot, Y$ & $r$ & $\cdot, i$ & 9 & 0 \\
\hline$r, \wedge \Lambda$ & 1 & $\cdot, \wedge$. & $\cdot, r \cdot$ & $r, 0$ &., $1 T$ & $r$ & $\cdot, \cdot V$ & 1 & $\cdot, \lambda$ & IT & $i$ \\
\hline$r, 97$ & 1 & $\cdot, 9 T$ & $\cdot, \cdot V$ & $r, 0$ & $\cdot, \cdot V$ & 1 & - & - & $\cdot, 9 T$ & $1 \leq$ & $\mathrm{v}$ \\
\hline$r, \lambda Y$ & 1 & $\cdot, V T$ & $\cdot, Y V$ & $r, 0$ &., $1 T$ & $r$ &., 15 & $r$ & $\cdot, V T$ & 11 & $\Lambda$ \\
\hline r,Vo & 1 & $\cdot, 7 \mathrm{~V}$ & $\cdot, T r$ & $T, 0$ & - & - & $\cdot, T r$ & 0 & $\cdot, \mathrm{iv}$ & 1. & 9 \\
\hline r,TV & 1 & $\cdot, 7$ & $\cdot, \leqslant$ & $r, 0$ & $\cdot, \cdot v$ & 1 & $\cdot, \Gamma T$ & 0 & $\cdot, 7$ & 9 & 1. \\
\hline$r, 07$ & 1 &., or & $\cdot, \leqslant V$ & $r, 0$ & - & - & $\cdot, \leqslant V$ & $\mathrm{~V}$ & $\cdot$, or & $\Lambda$ & 11 \\
\hline T,TV & 1 & $\cdot i$ & $\cdot, \leqslant$ & $r, 0$ & $\cdot, \cdot V$ & 1 & $\cdot, r T$ & 0 & $\cdot, i$ & 9 & $1 \%$ \\
\hline$r, \Lambda Y$ & 1 & $\cdot, V T$ & $\cdot r V$ & $r, 0$ & $\therefore, \cdot V$ & 1 & $\cdot, r$ & $r$ & $\cdot, \mathrm{Vr}$ & 11 & 14 \\
\hline$r, q T$ & 1 & $\cdot, \wedge \vee$ &., $1 T$ & $r, 0$ & $\cdot, \cdot V$ & 1 & $\cdot, \cdot V$ & 1 & $\cdot, \wedge \mathrm{V}$ & 15 & $1 \leqslant$ \\
\hline
\end{tabular}


جدول رقم (V): درجات الصدق المنطقي لعبارت مقياس مهارات التحثث الفعال لمرشدي القرى.

\begin{tabular}{|c|c|c|c|c|c|c|c|c|c|c|c|}
\hline \multirow{2}{*}{ المندقَ } & \multirow[b]{2}{*}{ s } & \multirow[b]{2}{*}{ س و } & \multirow[b]{2}{*}{ هـ س } & \multirow[b]{2}{*}{$\tau$} & \multicolumn{2}{|c|}{ غير صالحة } & \multicolumn{2}{|c|}{ صالحةٌ لعا ما } & \multicolumn{2}{|c|}{ صالحةٌ تماما } & \multirow[b]{2}{*}{ P } \\
\hline & & & & & $\%$ & عدد & $\%$ & عدد & $\%$ & عدد & \\
\hline$r, \lambda \Lambda$ & 1 & $\cdot, \lambda$ & $\cdot, r \cdot$ & $r, 0$ & $\cdot, 1 r$ & $r$ & $\cdot, \cdot v$ & 1 & $\cdot, \wedge$. & $1 T$ & 1 \\
\hline$r, \lambda Y$ & 1 & $\cdot, \mathrm{Vr}$ & $\cdot, r V$ & $r, 0$ & - & - & $\cdot, Y \mathrm{~V}$ & 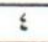 & $\cdot, V T$ & 11 & $r$ \\
\hline$r, \lambda$ & 1 & $\cdot \wedge$. & $\cdot r, T$ & $r, 0$ & - & - & $\cdot, r$. & $r$ & $\cdot, \wedge$. & $1 T$ & $r$ \\
\hline$r, 9 r$ & 1 & $\cdot, \lambda V$ & $\cdot, 1 r$ & $r, 0$ & $\cdot, \cdot V$ & 1 & $\cdot, \cdot V$ & 1 & $\cdot, \wedge \mathrm{V}$ & IT & $\varepsilon$ \\
\hline T,TY & 1 & $\cdot, i$ & $\cdot, \vdots$ & $T, 0$ & $\cdot, \cdot V$ & 1 & $\cdot, r T$ & 0 & $\cdot, 7$ & 9 & 0 \\
\hline$r, \ldots$ & 1 & $1, \ldots$ & - & $r, 0$ & - & - & - & - & $1, \cdots$ & 10 & 1 \\
\hline$T, 9 T$ & 1 & $\cdot$, AV &., 15 & $r, 0$ & $\theta, 1 T$ & $r$ & - & - & $\cdot, \wedge \mathrm{V}$ & IT & $\mathrm{V}$ \\
\hline$r, \lambda r$ & 1 & $\cdot, V T$ & $\cdot r^{r V}$ & $r, 0$ & $\cdot, r$. & $r$ & $\cdot, \cdot v$ & 1 & $\cdot, \mathrm{VT}$ & 11 & $\Lambda$ \\
\hline$r, 10$ & $i$ & $\cdot, i \mathrm{~V}$ & $\cdot, r T$ & $r, 0$ & $\cdot, \mathrm{r}$. & $r$ & $\cdot, 1 T$ & $r$ & $\cdot, 7 \mathrm{~V}$ & 1. & 9 \\
\hline$r, \lambda$ & $i$ & $\cdot, \lambda$ & $\cdot, r^{r}$ & $r, 0$ & - & - & $\cdot, r$. & $r$ & $\cdot, \wedge$. & Ir & 1. \\
\hline$r \ldots$ & $i$ & $1, \ldots$ & - & $r, 0$ & - & - & - & - & $1, \ldots$ & 10 & 11 \\
\hline $7, r=$ & $\overline{1}$ & $\cdot, i v$ & $\cdot, \Gamma r$ & $r, z$ & $\cdot, r$. & $r$ &., $1 T$ & $r$ & $\cdot$, iv & 1. & $1 \%$ \\
\hline
\end{tabular}

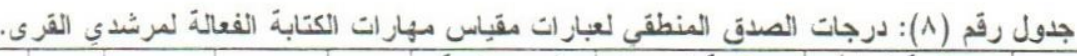

\begin{tabular}{|c|c|c|c|c|c|c|c|c|c|c|c|}
\hline \multirow{2}{*}{ المعدق } & \multirow[b]{2}{*}{$s$} & \multirow[b]{2}{*}{ س و } & \multirow[b]{2}{*}{ س سج } & \multirow[b]{2}{*}{$\tau$} & \multicolumn{2}{|c|}{ غير صاحة } & \multicolumn{2}{|c|}{ صالحة لحذ ما } & \multicolumn{2}{|c|}{ صالحة تمامَا } & \multirow[b]{2}{*}{$?$} \\
\hline & & & & & $\%$ & عد: & $\%$ & عدد & $\%$ & عدد & \\
\hline$r, \lambda \wedge$ & 1 & $\cdot, \wedge$. & $\cdot, r^{\prime}$ & $r, 0$ & $\cdot, \cdot V$ & 1 & $\cdot, 1 r$ & Y & $\cdot, \wedge$ & IT & 1 \\
\hline$r, 9 T$ & 1 & $\cdot, \wedge \mathrm{V}$ & $\cdot, 1 r$ & $r, 0$ & $\cdot, \cdot V$ & 1 & $\cdot, \cdot V$ & 1 & $\cdot, \wedge \mathrm{\vee}$ & 15 & $T$ \\
\hline$r, 97$ & 1 & $\cdot, 9 T$ & $\cdot, \cdot V$ & $r, 0$ & $\cdot, \cdot V$ & 1 & - & - & $\cdot, 91$ & 15 & $r$ \\
\hline$T, T V$ & 1 & 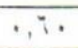 & $\cdot, \varsigma$ & $r, 0$ & - & - & $\cdot, \leqslant$ & $i$ & $\cdot, i$. & 9 & $\xi$ \\
\hline$r, \lambda Y$ & 1 & $\cdot, V T$ & $\cdot, \Gamma V$ & $r, 0$ & $\cdot, \cdot V$ & 1 & $\cdot, Y \cdot$ & $r$ & $\cdot, \mathrm{VT}$ & 11 & 0 \\
\hline$r, \wedge \lambda$ & 1 & $\cdot, 9 \mathrm{~V}$ &., 15 & $r, 0$ & $\cdot, \cdot V$ & 1 & $\cdot, \cdot V$ & 1 & $\cdot, \wedge \mathrm{V}$ & 11 & 1 \\
\hline$r, \ldots$ & 1 & $\cdot, \therefore$ & $\cdot, r^{\prime}$ & $r, 0$ & $\cdot, r$ & $r$ & - & - & $\cdot, \wedge$. & IT & $\mathrm{V}$ \\
\hline$r, i v$ & 1 & $\cdot i$ & $\cdot, \hat{\varepsilon}$ & $r, 0$ & $\cdot, \cdot V$ & 1 & $\cdot, \pi T$ & 0 & $\cdot, i$. & 9 & $\Lambda$ \\
\hline$r, 97$ & 1 & $\cdot, 9 T$ & $\cdot, \cdot V$ & $r, 0$ & - & - & $\cdot, \cdot V$ & 1 & $\cdot, 94$ & $1 \leq$ & 9 \\
\hline$r, 0$. & 1 & $1, \ldots$ & - & $T, 0$ & - & - & - & - & $1, \cdots$ & 10 & 1. \\
\hline$r, 97$ & 1 &., $9 r$ & $\cdot, \cdot V$ & $r, 0$ & - & - & $\therefore, v$ & 1 & $\cdot, 94$ & 15 & 11 \\
\hline$T, Y 0$ & 1 & $\cdot$, iv & $\cdot, r T$ & $T, 0$ & - & - & $\cdot, T r$ & 0 & $\cdot, \mathrm{TV}$ & 1. & 17 \\
\hline$r, \wedge \wedge$ & 1 & $\cdot, \wedge$ & $\cdot, r$. & $r, 0$ & $\cdot, 15$ & $r$ & $\cdot, \cdot V$ & 1 & $\cdot, \wedge$. & $1 T$ & 14 \\
\hline$r, \lambda Y$ & 1 & $\cdot, V T$ & $\cdot, T V$ & $r, 0$ & $\cdot, \cdot V$ & 1 & $\cdot, r \cdot$ & $r$ & $\cdot, \mathrm{Vr}$ & 11 & $1 \leqslant$ \\
\hline$T, 97$ & 1 & $\cdot, 9 T$ & $\cdot, \cdot V$ & $r, 0$ & - & - & $\cdot, \cdot V$ & 1 & $\cdot, 94$ & $1 \leq$ & 10 \\
\hline$r, 97$ & 1 & $\cdot, 91$ & $\cdot, \cdot V$ & $T, 0$ & - & - & $\cdot, \cdot V$ & 1 & $\cdot, 91$ & $1 \leq$ & 17 \\
\hline
\end{tabular}

جذول رقم (9): المصفوفة الإرتباطية بين مكونات مقبِاس المهارات الأساسيةَ لمرشدي القرى باجماسي المقبِاس.

\begin{tabular}{|c|c|c|c|c|}
\hline 1 & $r$ & $r$ & $\leqslant$ & مكونـات المقياس \\
\hline- & $\cdot$, io & $\cdot, \mathrm{V} \leq$ & $\cdot, \wedge \wedge$ & 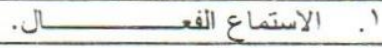 \\
\hline & - & $\cdot, \mathrm{it}$ & $\cdot, \wedge$ & 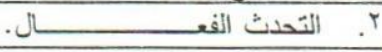 \\
\hline & & - & $\cdot, \wedge \vee$ & 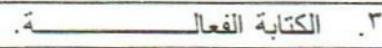 \\
\hline & & & - & 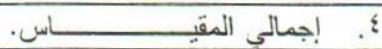 \\
\hline
\end{tabular}




\section{J. Agric. Sci. Mansoura Univ., 30(11), November, 2005}

ج- قدرة المقياس على التمييز Discrimination: يعد التحقق من قدرة المقياس علي التمييز احد أهم الخصائص التي تصف التصف المقياس الجيد، وقد

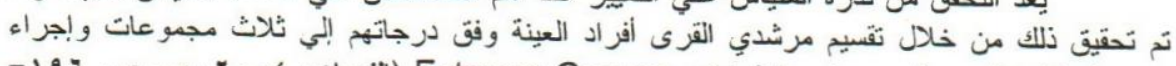

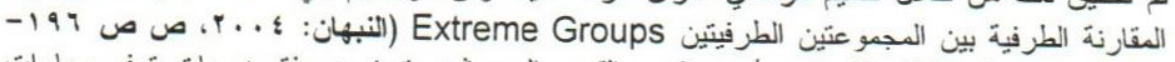

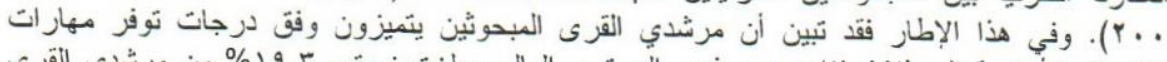

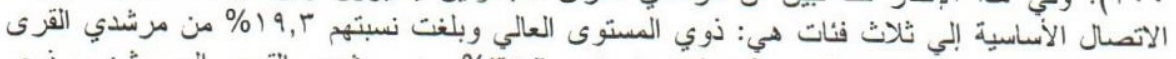

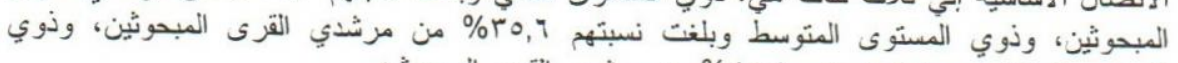

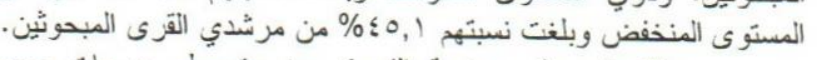

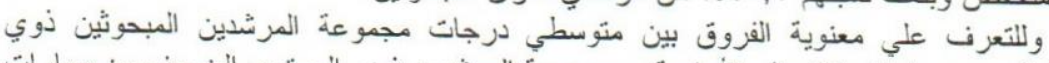

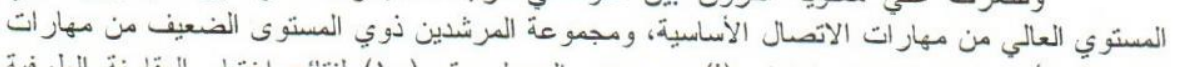

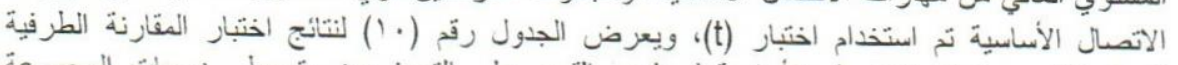

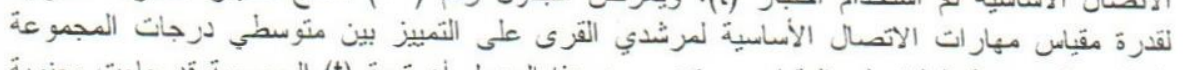

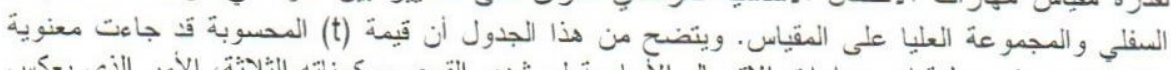

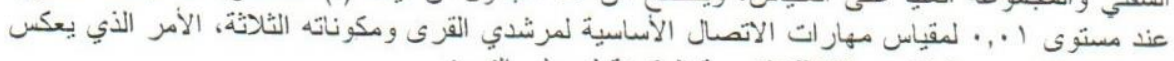

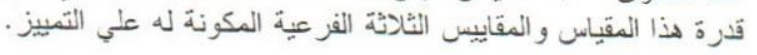

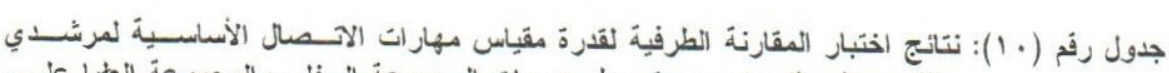

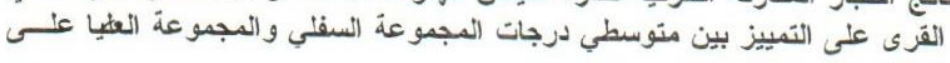

\begin{tabular}{|c|c|c|c|c|}
\hline \multirow{2}{*}{ مسنتويةً } & \multirow{2}{*}{ كَيمةَ } & \multicolumn{2}{|c|}{ منتوسط درجات } & \multirow{2}{*}{ مكونات المقياس } \\
\hline & & المجموعة العليا & المجموعة السفلي & \\
\hline$\cdot, \cdots$ & 19,5 & $r q, r$ & $\mid V, 1$ & 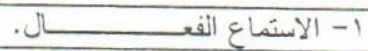 \\
\hline$\therefore, \cdots$ & $r \cdot, i$ & $r V, \lambda$ & $1 v, 7$ & ب- التحدث الفعــــــــال. \\
\hline$\cdot, \cdots$ & $10, \mathrm{~V}$ & $r T, v$ & $Y_{\cdot}, \cdot$ & 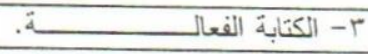 \\
\hline$\cdot, \cdots$ & $1 \mathrm{in,T}$ & $\Lambda 9, r$ & ov, & إجمالي المقياس \\
\hline
\end{tabular}

د- تجاتس نصفي المقياس Split-Half

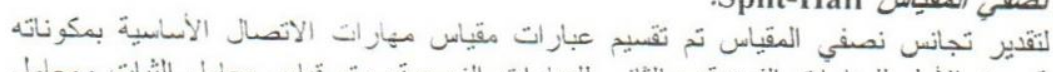

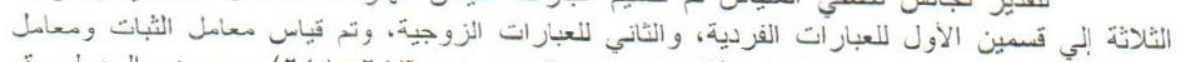

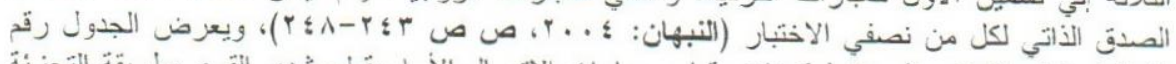

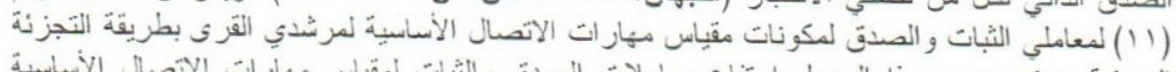

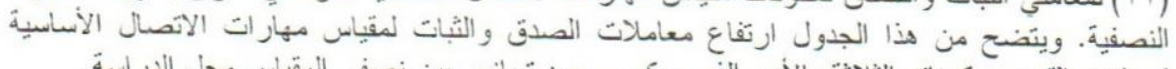

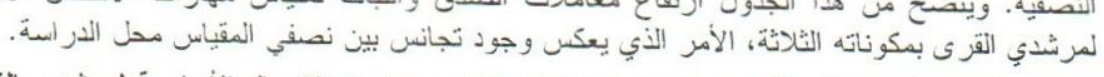

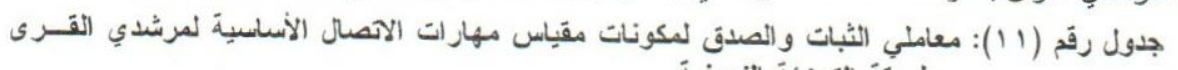
بطريقِة التجزئنة النصفيةة.

\begin{tabular}{|c|c|c|c|c|}
\hline \multirow{2}{*}{\multicolumn{2}{|c|}{ النصف الثاني من المقياس }} & & & \\
\hline & & \multicolumn{2}{|c|}{ النصف الأول من المقياس } & \multirow{2}{*}{ مكونات المقياس } \\
\hline معامل الصدق & معامل الثبات & معامل الصدق & معامل الثبات & \\
\hline$\cdot, 107$ & $\cdot, \mathrm{V} \vee \mathrm{T}$ & $\cdot, \wedge \vee \wedge$ & $\cdot, \mathrm{V} \vee 1$ & 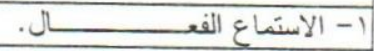 \\
\hline$\cdot, 9 \wedge$. & $\cdot, 97$. & $\cdot, \mathrm{V} \vee \leq$ & $\cdot, 7 \ldots$ & 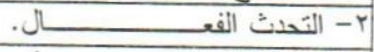 \\
\hline$\cdot, 179$ & $\cdot, \mathrm{VOT}$ & $\cdot, \wedge 71$ & $\cdot, \mathrm{V} 0 \leq$ & r- الكتابة الفعالــــا \\
\hline$\cdot, 9 \cdot 1$ & $\cdot$, ATr & $\cdot, 9 \cdot r$ & $\cdot, \Lambda 1 r$ & إجمالي المقياس \\
\hline
\end{tabular}

و-كفاءة المقياس Scale Effectiveness

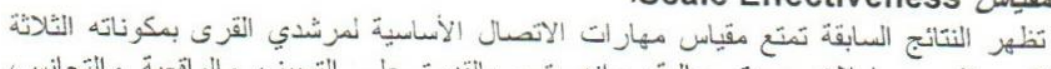

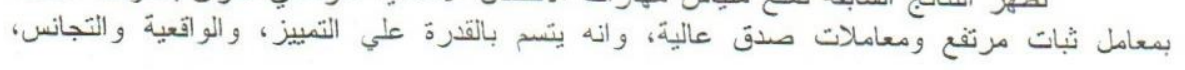




\section{Abd El-Magieed, M.A.M. and A.H.M. El-Said}

وبالإضافة لذلك تظهر النتائج السابقة أيضا كفاءة المقياس أي قدرة وحداته لتحقيق الهدف منها، وذلك كما

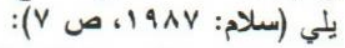

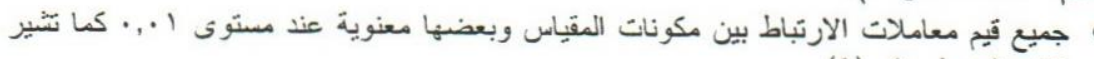

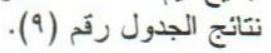

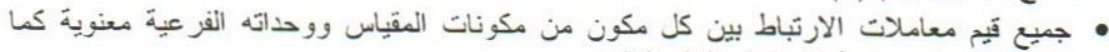

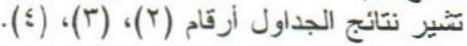

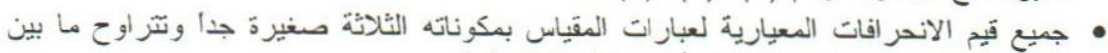

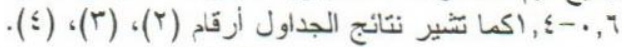

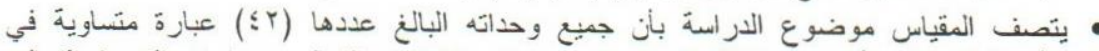

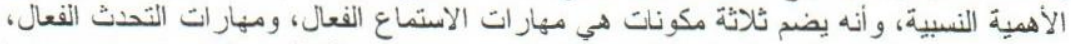

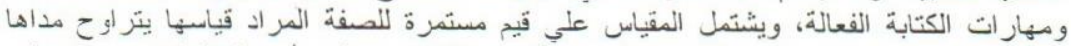

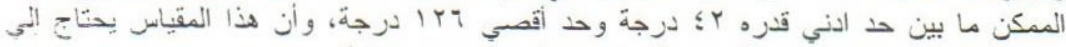

إعادة تقنين علي فتز ات زمنية متثابعة وفي مناطق متعندة ومنتباينة.

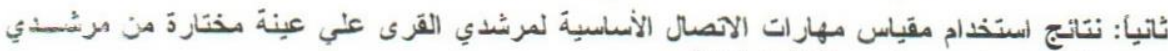

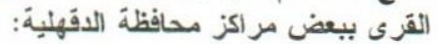

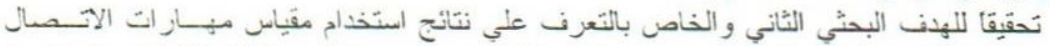

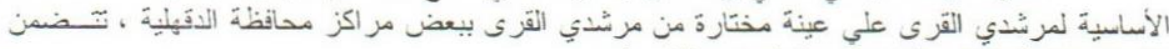

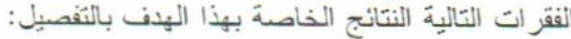

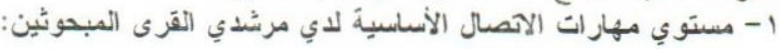

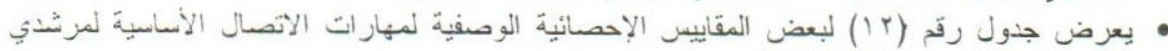
القزى المبحوثين بمحافظة الدقولية.

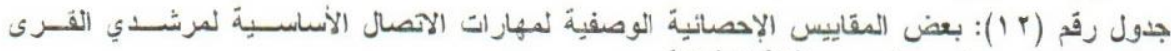
المبحوثين بمحافظة الدقولبية.

\begin{tabular}{|c|c|c|c|c|c|}
\hline \multirow{2}{*}{ الاختلف معامل } & \multirow{2}{*}{ الأنَّو اءمل } & \multirow[b]{2}{*}{ المنوسط } & \multicolumn{2}{|c|}{ ألمدى } & \multirow[b]{2}{*}{ مبرات الاتصل الأساسية العدروسة } \\
\hline & & & قَبِمة & قَيمة ألَ & \\
\hline \multicolumn{6}{|r|}{ أولا: مهارات الاسنماع الفعال: } \\
\hline$\Gamma A, Y$ & $\cdot, \bar{T}$ & $T, 1$ & i & $T$ & 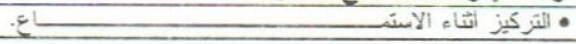 \\
\hline$r 0, r$ & $\cdot, 0 \leq$ & $r, \vdots$ & $i$ & $T$ & • فب موضورع المحانئن \\
\hline$r i, r$ & $\cdot, 01$ & $\$, \Lambda$ & 9 & $T$ & 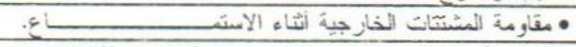 \\
\hline$r \cdot, i$ & $\cdot, \lambda T$ & $i, Y$ & $1 \%$ & $\leqslant$ & 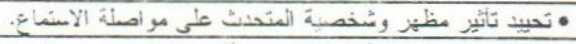 \\
\hline$r v, 1$ & $r, i$ & 6,1 & 9 & $r$ & 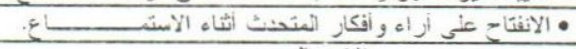 \\
\hline$r+r$ & $\cdot, V_{7}$ & $r+r$ & \& & $1 \leqslant$ & 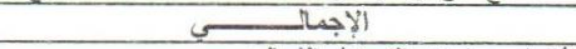 \\
\hline \multicolumn{6}{|r|}{ يُاتيا: مهارات التحدث الفعال: } \\
\hline$r \wedge, r$ & $\cdot, \cdot V$ & $r, 9$ & i & r & 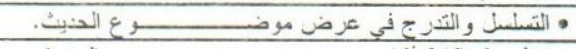 \\
\hline$r T, V$ &., 10 & $0, Y$ & 9 & $r$ & 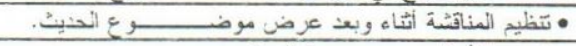 \\
\hline$T \wedge, 9$ & $\cdot, 1 \cdot$ & $\Gamma, \lambda$ & $i$ & T & •توجيه الأسئل \\
\hline$r i, \lambda$ & $\cdot,+r T$ & $\Gamma, \lambda$ & $i$ & T & • الإجابة على أمسئلة المستمعيس \\
\hline$T \cdot, T$ & $\therefore, 10$ & $0, r$ & 9 & $r$ & 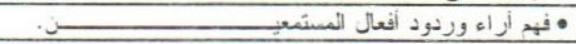 \\
\hline 11,0 & $\cdot$, Or & $r+1$ & $r 9$ & ir & الإجماسا \\
\hline \multicolumn{6}{|r|}{ نَآثا: مهارات الكتابة الفعالة: } \\
\hline$r \cdot, 9$ & $\cdot, \vdots$ & $\Lambda, i$ & it & $\leqslant$ & 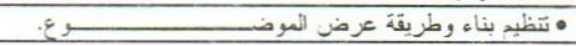 \\
\hline rt, & $\cdot, 17$ & $\varsigma, \lambda$ & 9 & $\Gamma$ & 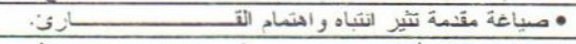 \\
\hline$r 1,1$ & $1, \cdot T$ & $\leqslant, 0$ & 9 & $r$ & 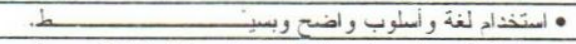 \\
\hline$r q, \gamma$ & $\cdot, i \cdot$ & $i, 5$ & ir & $\leqslant$ & • مر اعاة الخصانص الممبزة للمسينُبنفين بالمادة المكتوبــــة. \\
\hline$r 9,5$ & $\cdot, \mathrm{VV}$ & $r, r$ & i & T & 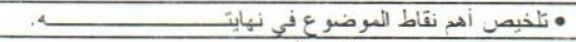 \\
\hline$r, 0$ & $1, \cdots$ & $r 0, \Lambda$ & $\{\Lambda$ & 17 & الإجمالـ \\
\hline $19, r$ &., $9 r$ & $\mathrm{~V} \cdot, \mathrm{r}$ & $1 \times 9$ & $\varepsilon r$ & إجهاتي مهار ات الاتصال الأساسية \\
\hline
\end{tabular}




\section{J. Agric. Sci. Mansoura Univ., 30(11), November, 2005}

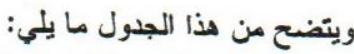

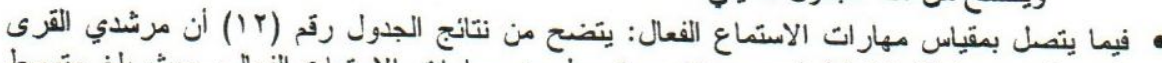

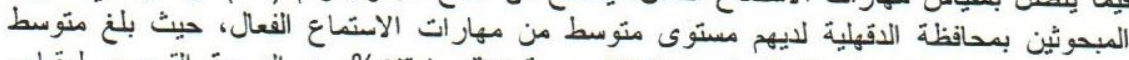

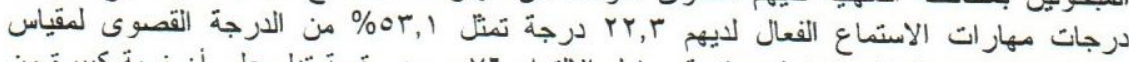

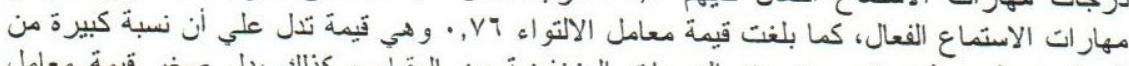

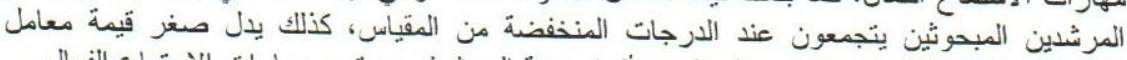

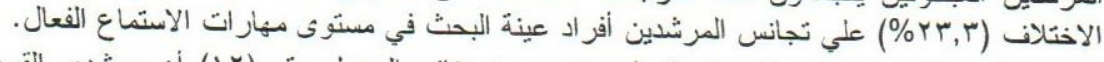

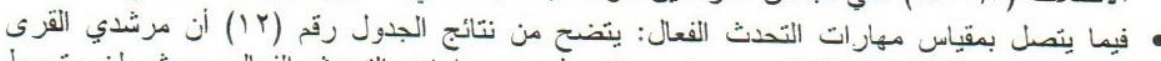

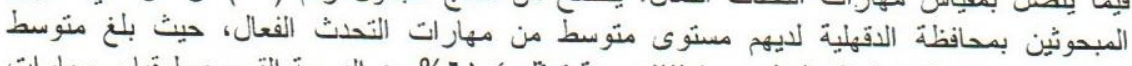

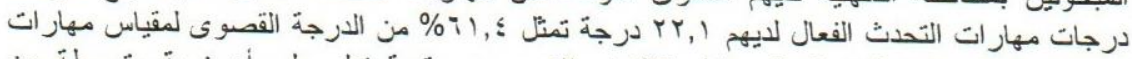

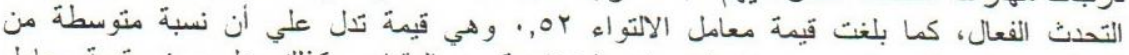

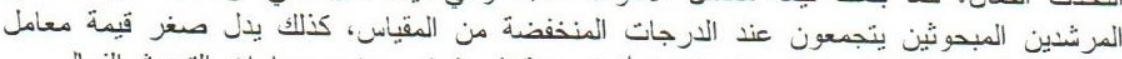

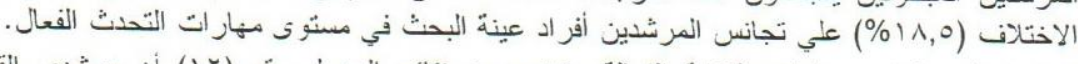

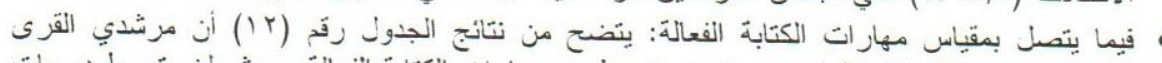

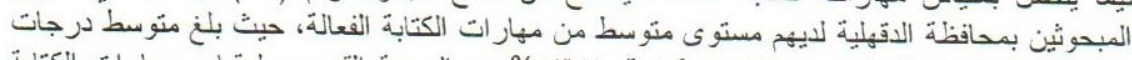

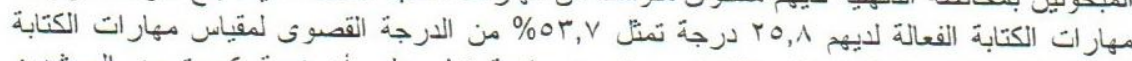

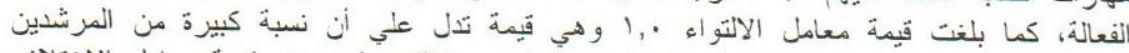

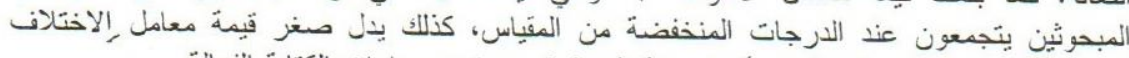

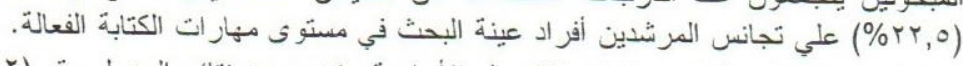

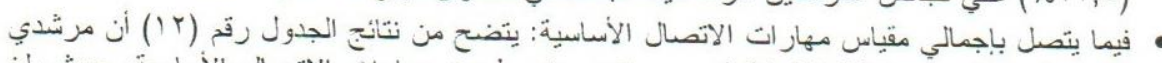

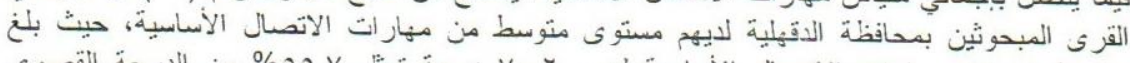

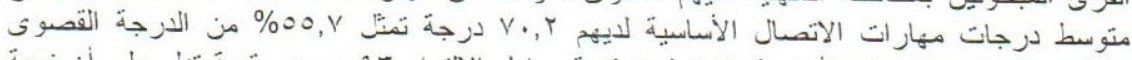

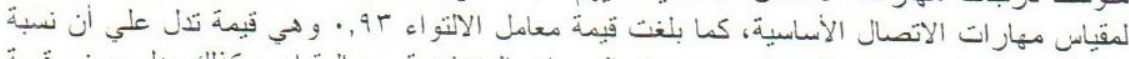

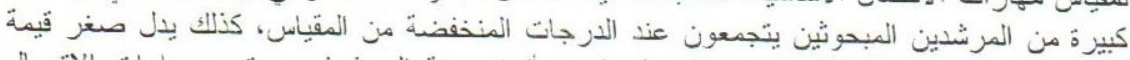

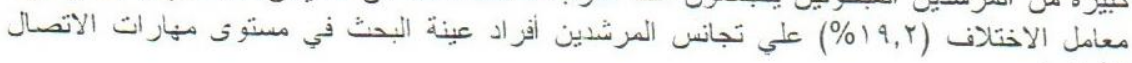

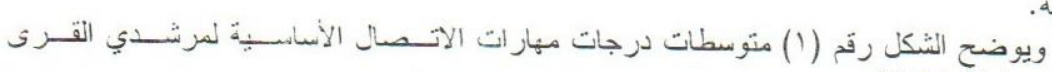
الأساسية. المبحوثين بمحافظة الدقهلية.

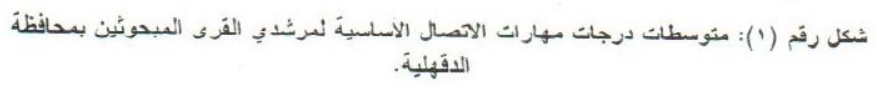

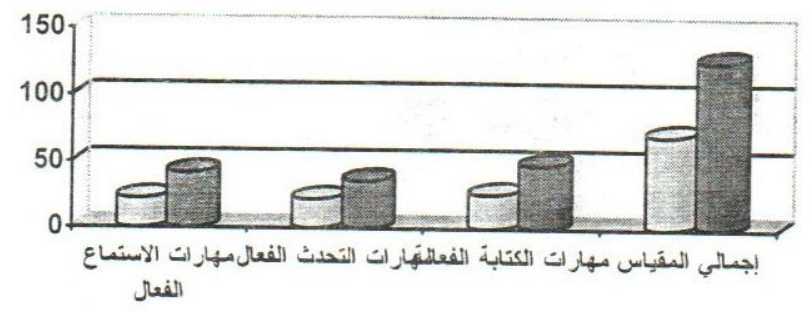

اللارجة القصوى للقيَاس هتوسط اللرجاته

r - الفروق بين نمط الاتصل الحالي لمرشدي المقرى المبحوثين و النمط المنتوقع مستقبلا:

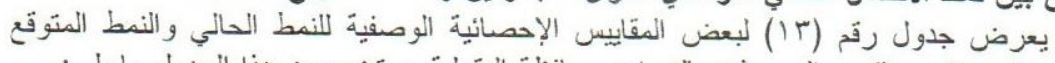

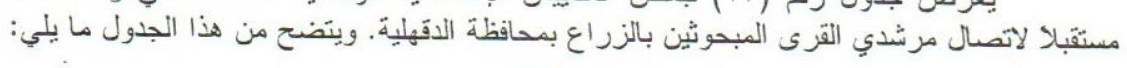




\section{Abd El-Magieed, M.A.M. and A.H.M. El-Said}

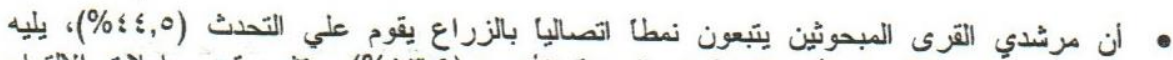

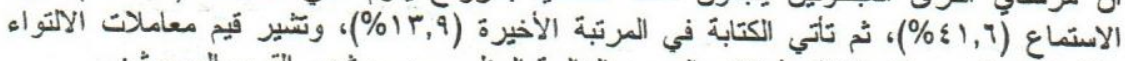

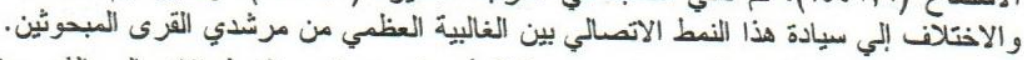

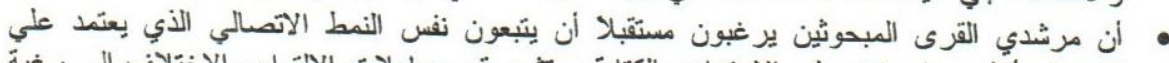

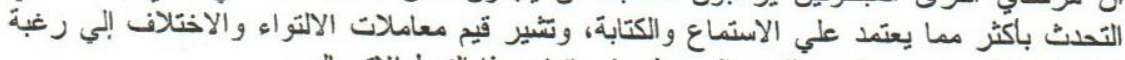

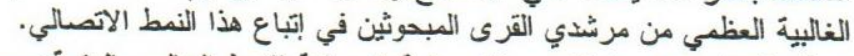

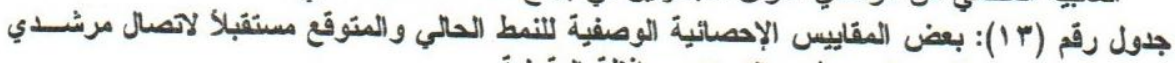

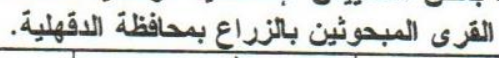

\begin{tabular}{|c|c|c|c|c|c|c|}
\hline \multirow{2}{*}{ الاختلاف معل \% } & \multirow{2}{*}{ معامل الالتواء } & \multirow{2}{*}{ المتوسط } & \multicolumn{2}{|c|}{ المدي } & \multirow{2}{*}{\multicolumn{2}{|c|}{ نمط الاتصال الإرشادي }} \\
\hline & & & أكبر قِيمة & ألزل قيمة & & \\
\hline & & & & & نمط الآصـال الحلــــي & .1 \\
\hline$r q, r$ & $\cdot, 0$ & $\sum 1,7$ & 10 & $1 \cdot$ & استماع. & $\bullet$ \\
\hline rT, : & $\cdot, 40$ & $\leq \leqslant, 0$ & 9. & $1 \cdot$ & تحدث. & $\bullet$ \\
\hline$v^{*}, r^{r}$ & Y,I & 15,9 & $\mathrm{ve}$ & - & كتابــة. & - \\
\hline & & & & & نمط الآصال المستَقبلي & $T$ \\
\hline$\$ 0,1$ & $\cdot, T Y$ & $r q, r$ & 90 & - & اسنماع. & - \\
\hline$\leq \cdot, i$ & $\cdot, \leqslant \wedge$ & $\{\leqslant, \xi$ & $1 \ldots$ & 0 & تحدث. & $\bullet$ \\
\hline $\mathrm{Vq}$, & $Y, Y$ & $10, \mathrm{~V}$ & 9. & $\cdot$ & كتابــة. & $\bullet$ \\
\hline
\end{tabular}

المصدر: استئمارت الاستبيان.

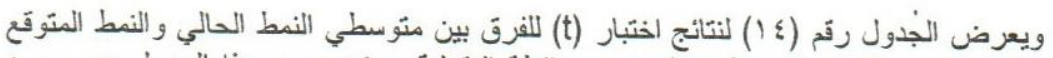

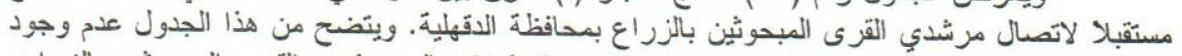

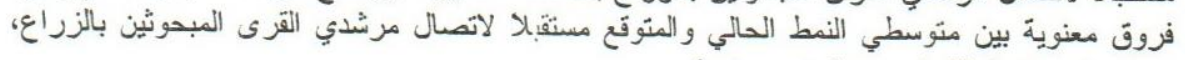

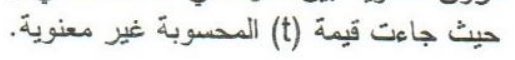

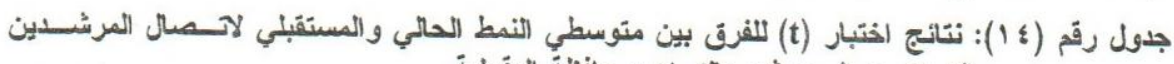

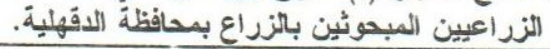

\begin{tabular}{|c|c|c|c|c|c|}
\hline \multirow{2}{*}{ المعنتويةِي } & \multirow{2}{*}{ قُ } & \multicolumn{2}{|c|}{ متوسط درجات } & \multirow{2}{*}{\multicolumn{2}{|c|}{ أسلوب الاتصال }} \\
\hline & & النمط المستقبَلي & النمط الحالمي & & \\
\hline$\cdot, Y$ & $1, Y$ & $r q, r$ & $\$ 1,7$ & استماع. & • \\
\hline $1, \cdot$ & $\cdot, Y$ & $\leqslant \leqslant, \leqslant$ & $\leqslant \leqslant, 0$ & تحنث. & - \\
\hline$\cdot, \cdot V$ & $1, \wedge$ & $10, Y$ & $1 r, 9$ & كتابــةة. & - \\
\hline
\end{tabular}

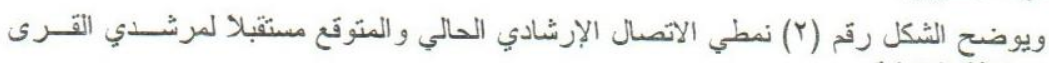
المبحوثين بمحافظة الدقهلية.

نمط الاتصال الإرشادي المستقبلي

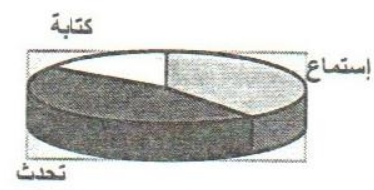

نمط الاتصال الإرشادي الحالمي

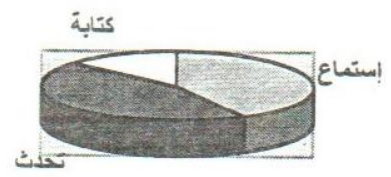




\section{J. Agric. Sci. Mansoura Univ., 30(11), November, 2005}

\section{الاستنتاجات الثرئيسية و التوصيات}

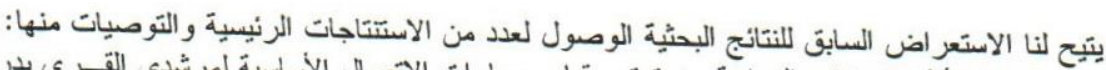

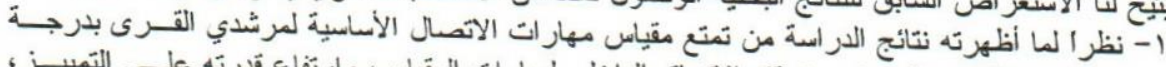

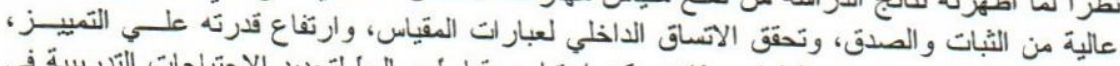

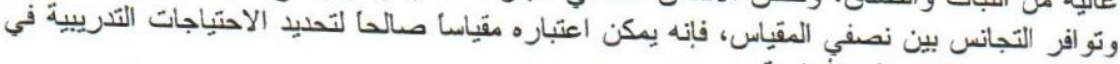
مجال مهار ات الاتصال الأسناسية.

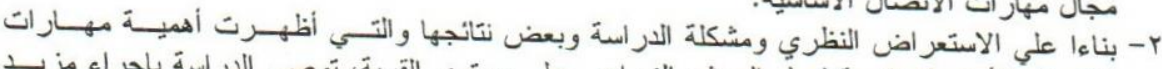

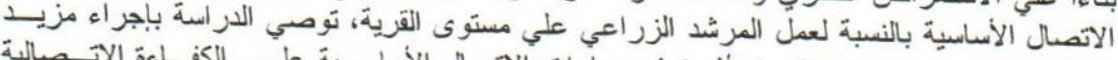

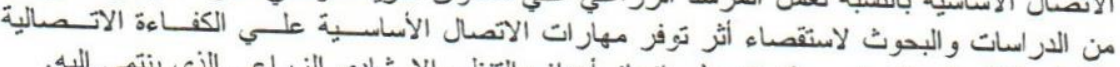

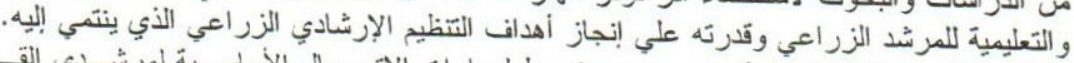

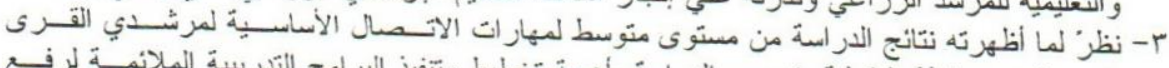

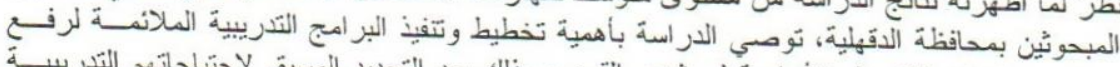

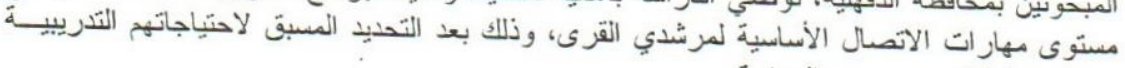

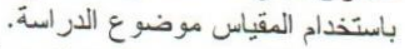

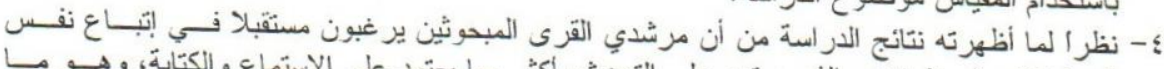

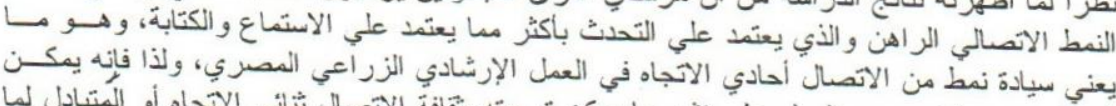

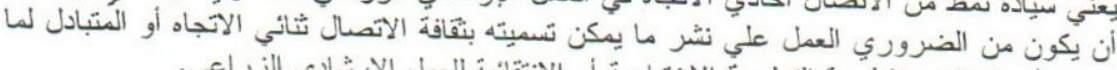

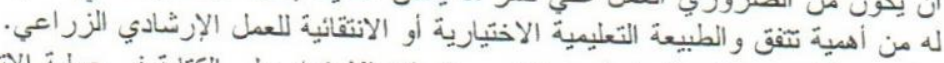

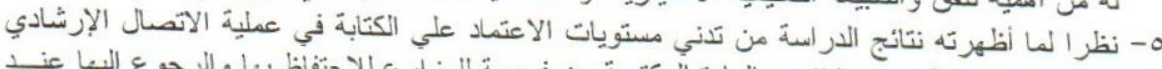

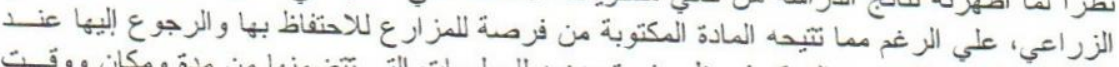

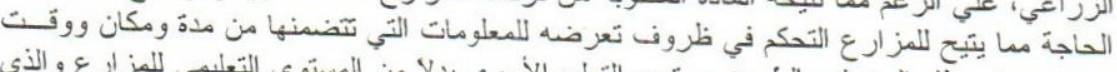

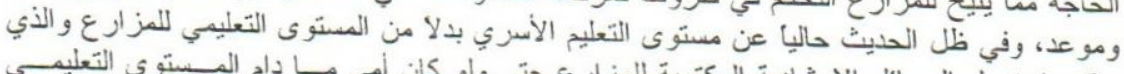

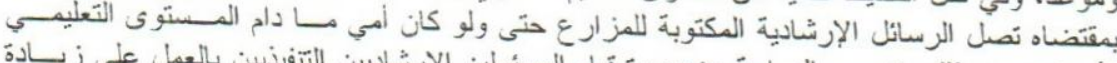

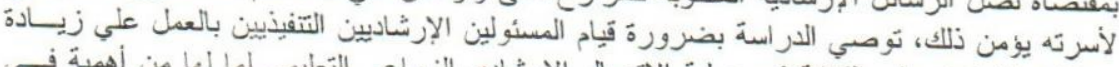

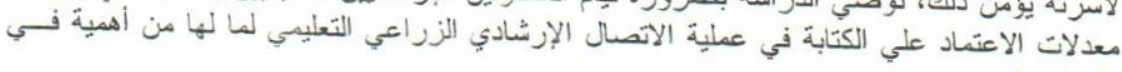
هذا المجال.

$$
\text { المراجع }
$$

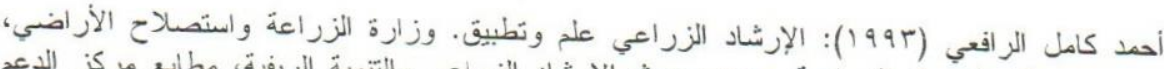

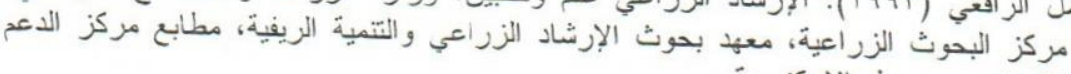
الإعلامي بمريوط، البحوث الزبكندرية.

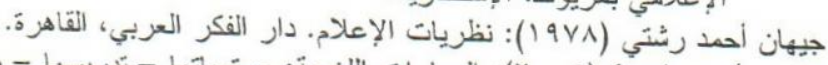

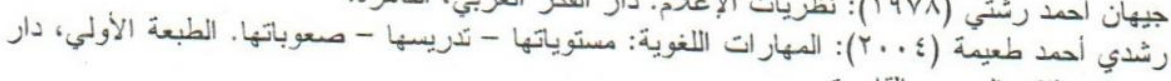

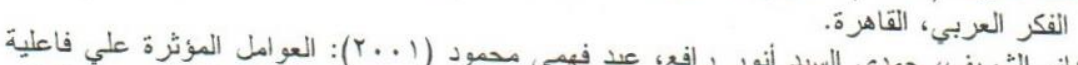

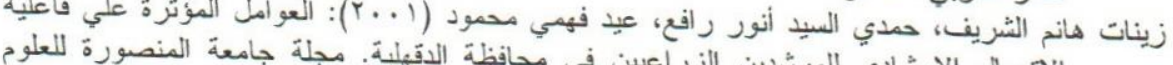

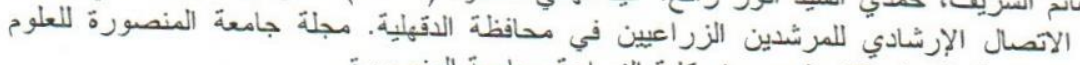

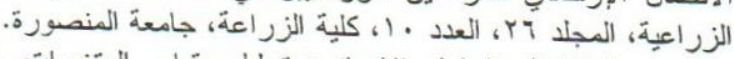

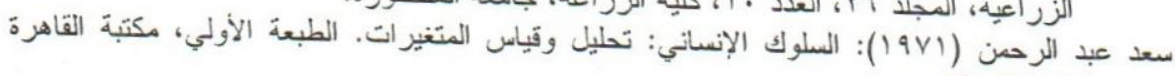

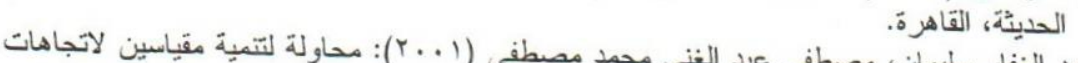

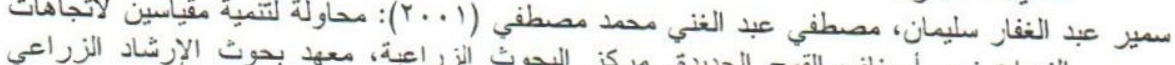

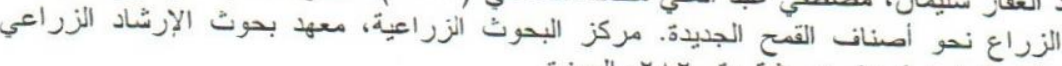

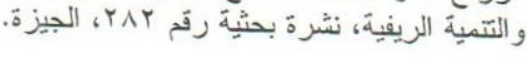




\section{Abd El-Magieed, M.A.M. and A.H.M. El-Said}

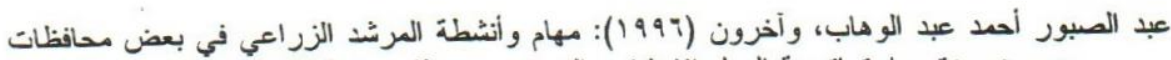

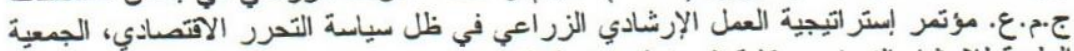

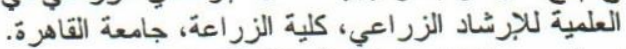

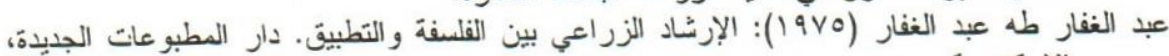
الإسكندرية.

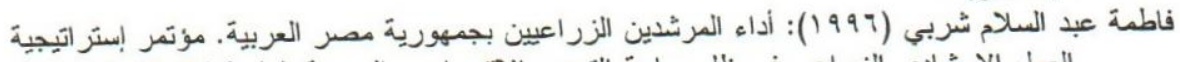

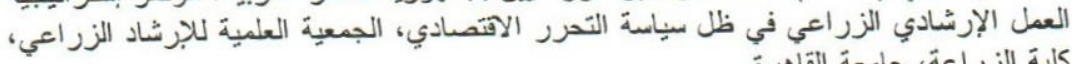

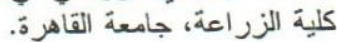

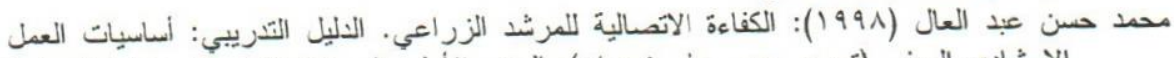

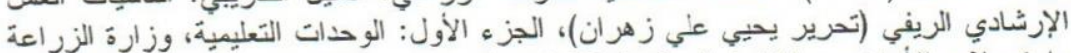

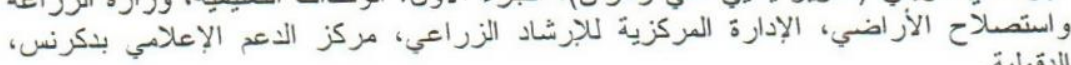

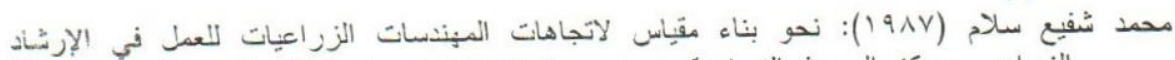

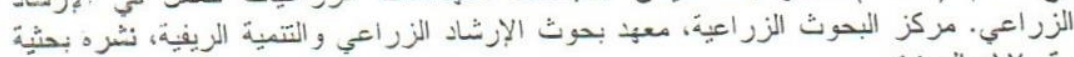
رقم VV الجيزة الجيزة.

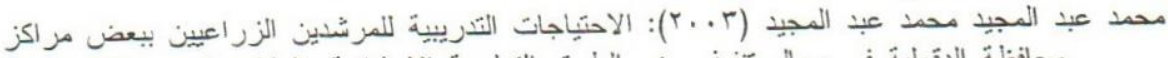

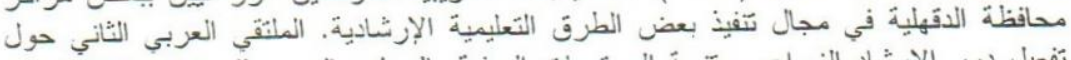

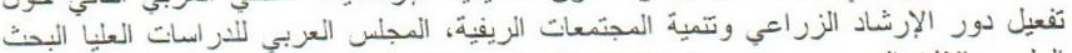

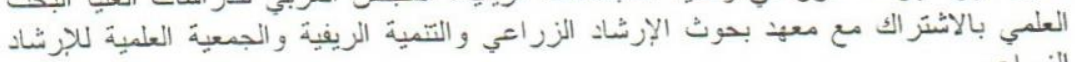

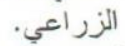
موسي النبهان (؛؛ ..ب): أساسيات القياس في العلوم السلوكية. الطبعة الأولي، دار الثروق للنشر

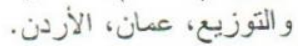

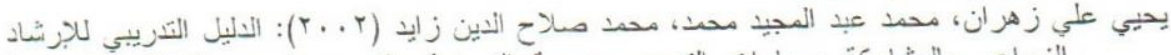

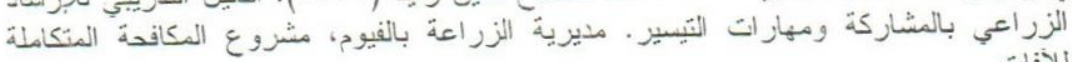
ل الكانات.

Cooper, A.W. and Graham, D.L. (2001): Competencies Needed to be Successful County Agents and County Supervisors. Journal of Extension [On-line]. 39(1). Available at: http://www.joe.org/joe/2001/februray/rb3. html.

Kessel, G. (1983): The Art of Good Writing. In: Carpenter, W.L. (Ed.), Communications Handbook, Fourth Edition, Agricultural Communicators in Education, USA.

Rogers, E.M. (1986): Communication Technology: The New Media in Society. Series in Communication Technology and Society. The Free Press, New York.

Taylor, H.R. (1983): Communication Concepts. In: Carpenter, W.L. (Ed.), Communications Handbook, Fourth Edition, Agricultural Communicators in Education, USA.

Walker, K., et al (2002): LEADS Curriculum Notebook. Kansas State University Agricultural Experiment Station and Cooperative Extension Services, USA. 


\title{
J. Agric. Sci. Mansoura Univ., 30(11), November, 2005
}

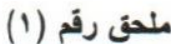

مقياس مهارات الاتصال الأساسية لمرشدي رقمي القرى في صورته النهانية

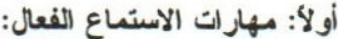

من فضلك أقرأ قائمة العبارات التالية جيدا. ثُ أختر إجابة واحدة من الإجابات الثُلاث المقابلة لكل سؤال لتعبر عن مدى قيامك بهذا السلوك من عدمه عند استماعك لحديث شخص ما ما (مزارع - زميل

\begin{tabular}{|c|c|c|c|}
\hline نادرا & أحياتا & دائما & العبارات \\
\hline & & & 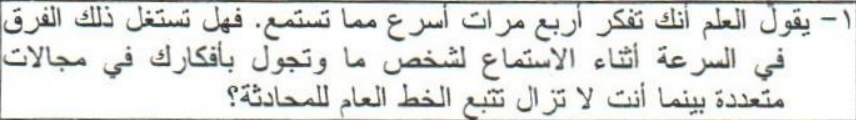 \\
\hline & & & 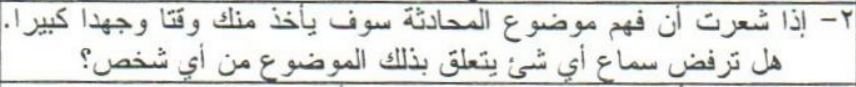 \\
\hline & & & 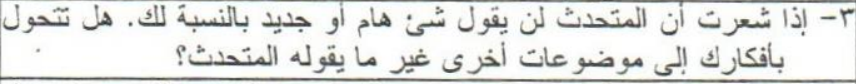 \\
\hline & & & 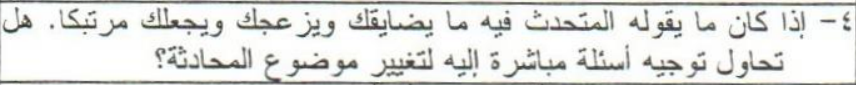 \\
\hline & & & 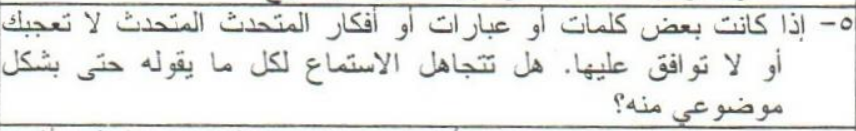 \\
\hline & & & 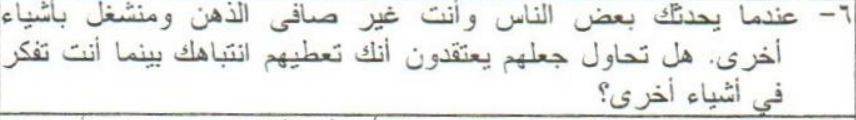 \\
\hline & & & 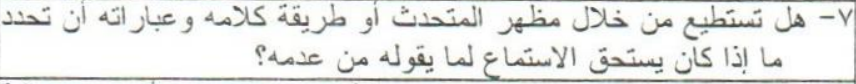 \\
\hline & & & 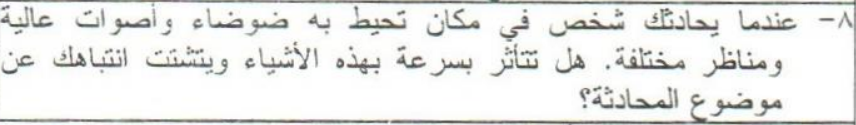 \\
\hline & & & 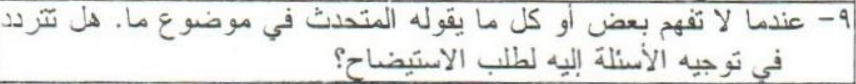 \\
\hline & & & 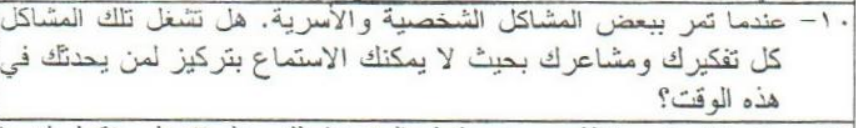 \\
\hline & & & 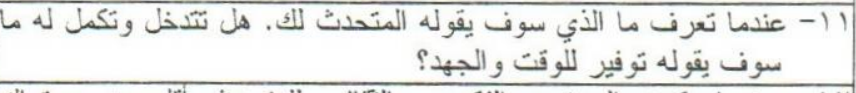 \\
\hline & & & 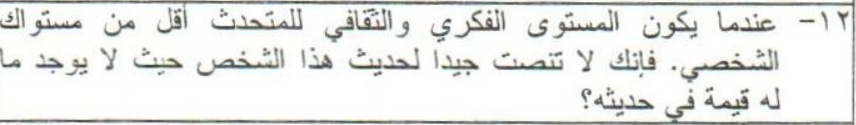 \\
\hline & & & 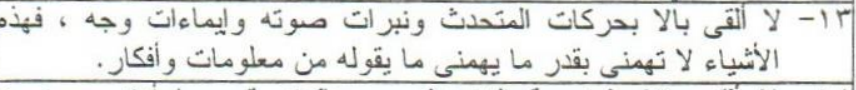 \\
\hline & & & 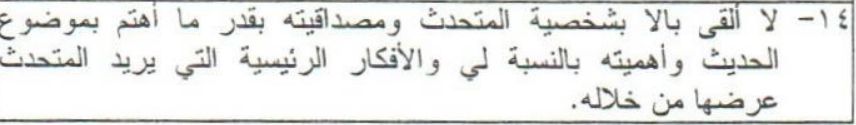 \\
\hline
\end{tabular}




\section{Abd El-Magieed, M.A.M. and A.H.M. El-Said}

ثاتيا : مهارات التحدث (الكلام) الفعال:

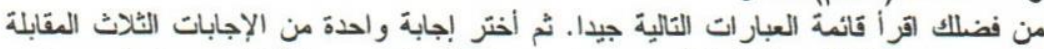

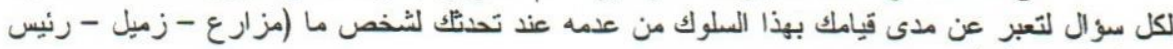

\begin{tabular}{|c|c|c|c|}
\hline نادرا & أحساتا & دانما & العبار ات \\
\hline & & & 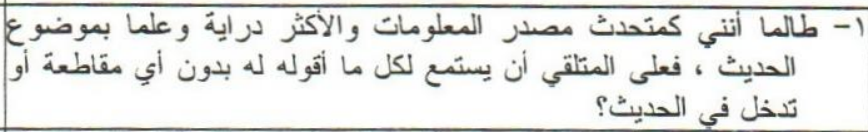 \\
\hline & & & 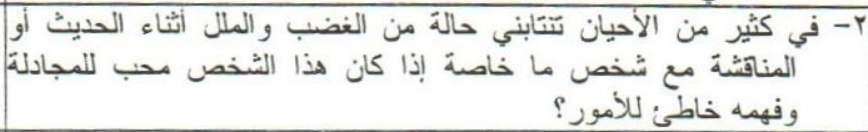 \\
\hline & & & 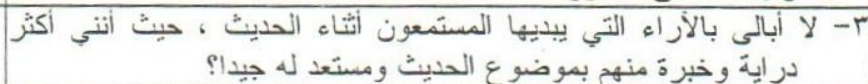 \\
\hline & & & 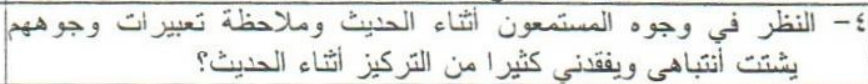 \\
\hline & & & 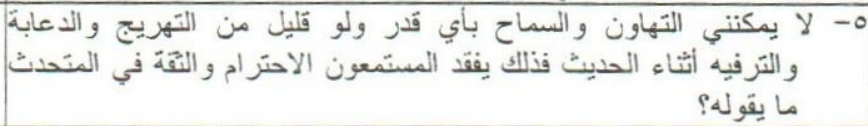 \\
\hline & & & 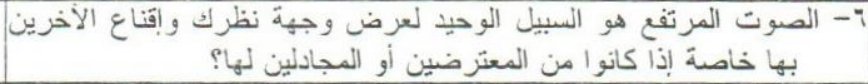 \\
\hline & & & 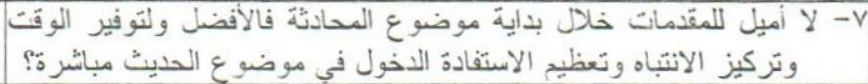 \\
\hline & & & 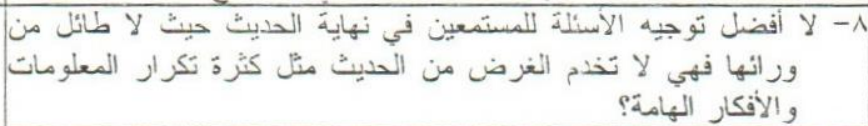 \\
\hline & & & 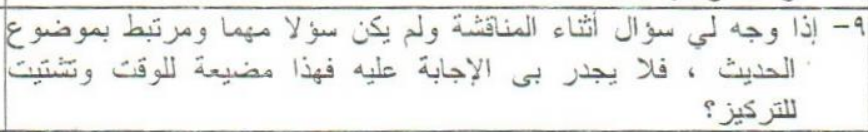 \\
\hline & & & 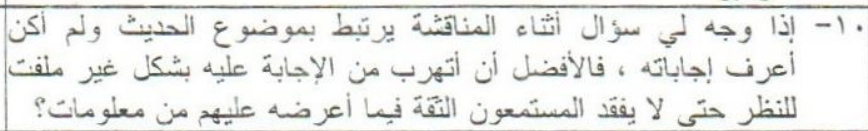 \\
\hline & & & 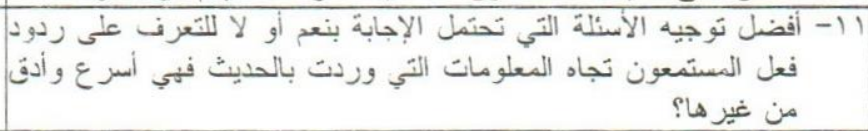 \\
\hline & & & 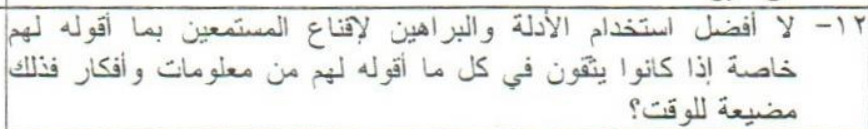 \\
\hline
\end{tabular}




\section{J. Agric. Sci. Mansoura Univ., 30(11), November, 2005}

ثلثا : مهارات العتلبة الفعلة:

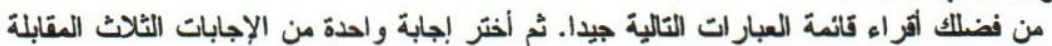

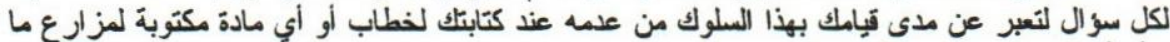

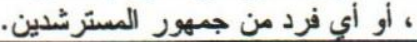

\begin{tabular}{|c|c|c|c|}
\hline نادرا & أحياتا & دائما & العبارات \\
\hline & & & 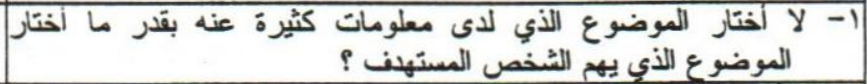 \\
\hline & & & 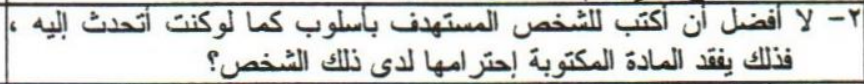 \\
\hline & & & 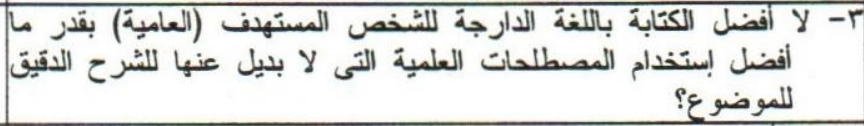 \\
\hline & & & 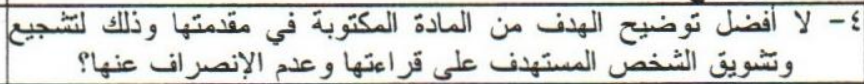 \\
\hline & & & 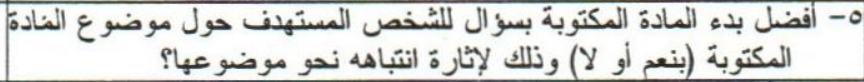 \\
\hline & & & 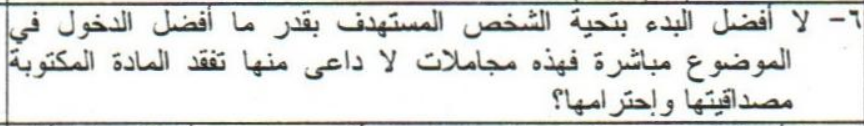 \\
\hline & & & 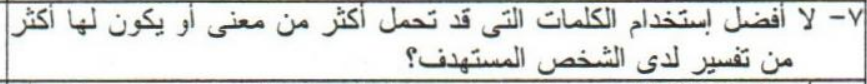 \\
\hline & & & 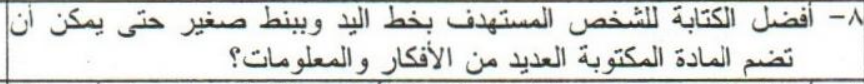 \\
\hline & & & 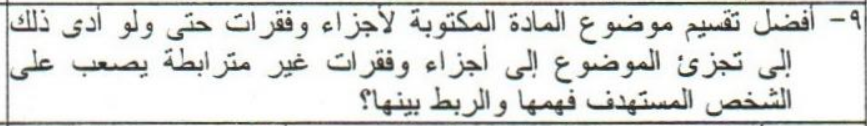 \\
\hline & & & 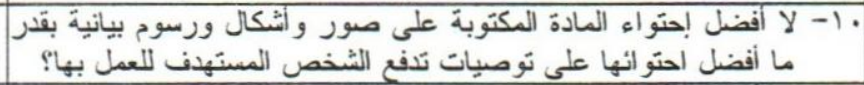 \\
\hline & & & 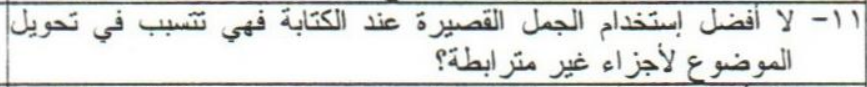 \\
\hline & & & 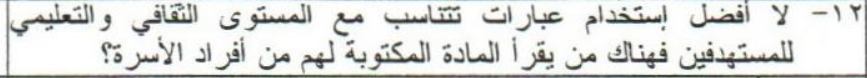 \\
\hline & & & 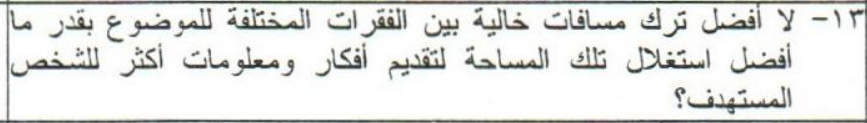 \\
\hline & & & 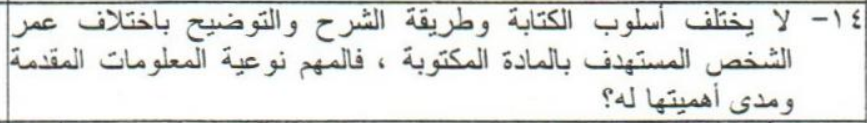 \\
\hline & & & 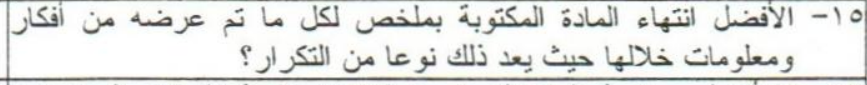 \\
\hline & & & 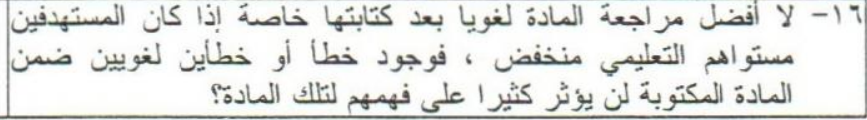 \\
\hline
\end{tabular}


DEVELOPING AND APPLYING A SCALE FOR MEASURING BASIC COMMUNICATION SKILLS OF VILLAGE EXTENSION WORKERS AT A.R.E. "A FIELD STUDY FOR VILLAGE EXTENSION WORKERS IN THREE DISTRICTS AT DAKAHLIA GOVERNORATE".

Abd El-Magieed, M.A.M.* and A.H.M. EL-Said**

* Agricultural Extension and Rural Society Dept., Faculty of Agriculture, University of Mansoura.

* Agricultural Economic Dept., Ismailia Faculty of Agriculture, University of Suez Canal.

\begin{abstract}
The current study aimed mainly to develop a scale for measuring basic communication skills of village extension workers at 4.R.E and to apply this scale after testing its validity in measuring basic communication skills of village extension workers in three districts at Dakahlia governorate.

The study was carried out in Belqas, Talkha and Meet Ghamr districts in Dakahlia governorate. The sample of the study was consists of eighty two VEW's who attended the weekly meeting which had been held in the sub-directorate in each selected district at the time of data collection. Data were collected by using personal interview questionnaire during the period from September to November 2004. Frequencies, Percentages, Range, Arithmetic Mean, Standard Deviation, Variance, Coefficient of Variation, Skewness, Pearson Correlation Coefficient, $t$ Test, Reliability and Validity Coefficients were used to analyze data statistically.

The main findings of this study indicated that:

1- The findings revealed that the scale of basic communication skills consists of $\mathbf{4 2}$ items having a high degree of reliability and validity.

2- The results of applying the developed scale on VEW's at Dakahlia governorate revealed that the interviewed VEW has a moderate level of basic communication skills, these skills are effective listening, effective speaking and effective writing.

3- Finally, the results indicated that the interviewed VEW's follow a communication behavior with farmers depending mainly on speaking more that listening and writing. Also, the findings indicated that the interviewed VEW's wish to follow the same communication behavior in the future.
\end{abstract}

